James Madison University JMU Scholarly Commons

Masters Theses

The Graduate School

Spring 2014

\title{
The effects of obstructive sleep apnea on autonomic function during steady-state exercise
}

Courtney Sutton

James Madison University

Follow this and additional works at: https://commons.lib.jmu.edu/master201019

Part of the Kinesiology Commons

\section{Recommended Citation}

Sutton, Courtney, "The effects of obstructive sleep apnea on autonomic function during steady-state exercise" (2014). Masters Theses. 344.

https://commons.lib.jmu.edu/master201019/344

This Thesis is brought to you for free and open access by the The Graduate School at JMU Scholarly Commons. It has been accepted for inclusion in Masters Theses by an authorized administrator of JMU Scholarly Commons. For more information, please contact dc_admin@jmu.edu. 
The Effects of Obstructive Sleep Apnea on Autonomic Function during

Steady-State Exercise

Courtney Sutton

A thesis submitted to the Graduate Faculty of

JAMES MADISON UNIVERSITY

In

Partial Fulfillment of the Requirements

for the degree of

Master of Science

Department of Kinesiology

May 2014 


\section{Acknowledgements}

I would like to thank Dr. Trent A. Hargens for his guidance and for being my Committee Chair. I am very appreciative for all of his support and feedback during this process. It has been a pleasure working with someone so well respected in the field of sleep apnea.

I would also like to extend my gratitude to Dr. Mikel K. Todd and Dr. Chris J. Womack for serving as members of my thesis committee. I am very thankful for their feedback and guidance.

Additionally, I would like to thank Dr. Nick D. Luden and Dr. Elizabeth S. Edwards for their words of wisdom and support throughout this process. I would also like to thank Joe Aiello, Ali Fracasso, and Matt Scott for their constant encouragement. I am thankful for Jake Ridings who has been my research partner during this thesis process.

Finally, I would like to thank my family and JJ Strosnider for their unfailing love, support, and prayers during my thesis and entire time of graduate school. I am also thankful for the love, hugs, laughs, and encouragement from Laura Shupe and Taylor Wenos-Rowley, they became my "family away from home." 


\section{Table of Contents}

Acknowledgements .......................................................................................

List of Tables ............................................................................................

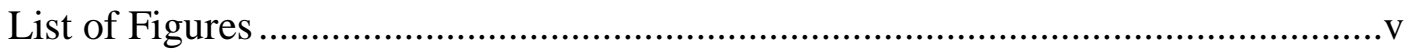

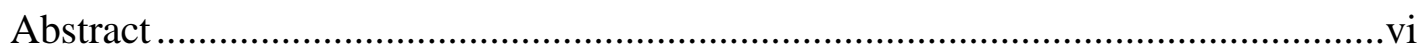

I. Introduction ........................................................................................

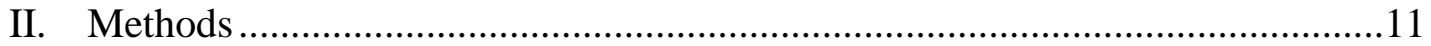

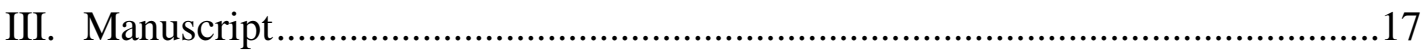

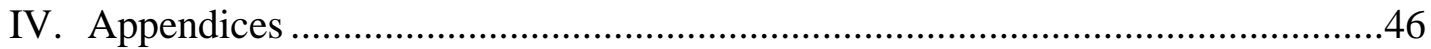

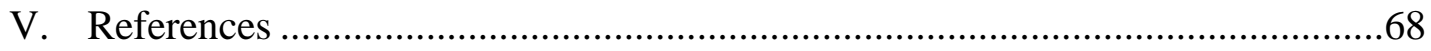




\section{List of Tables}

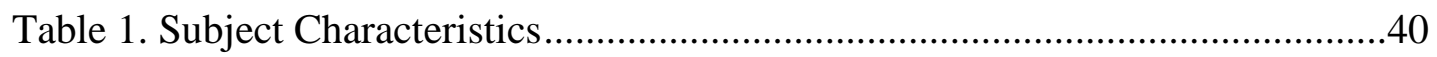

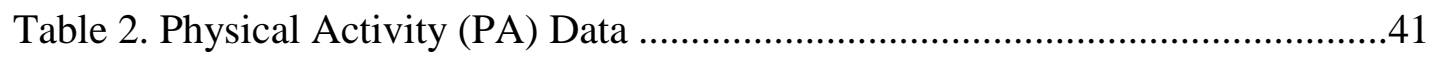

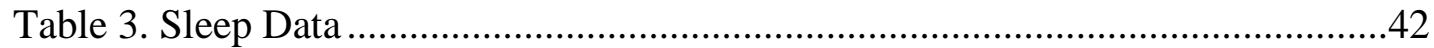

Table 4. Oxygen Consumption .................................................................43

Table 5. Heart Rate Variability (HRV) Data .......................................................44 


\section{List of Figures}

Figure 1. LFnu (A), HFnu (B), and LF-HF Ratio (C)

between OSA and Control at rest, light intensity, and vigorous intensity .........45 


\begin{abstract}
Purpose The aim of this study is to assess autonomic function by analyzing heart rate variability (HRV) at rest and during submaximal exercise in OSA patients and a nonOSA control group.

Methods Subjects were classified as OSA $(\mathrm{n}=10)$ or non-OSA $(\mathrm{n}=16)$ based on results from an at-home sleep assessment. Height, weight, waist and neck circumferences, and body composition were collected during the first visit for each subject. Physical activity during the day and nocturnal movement were assessed over a period of 4 days, including 3 weekdays and 1 weekend day, using accelerometers. HRV and blood pressure were recorded at rest (visit 2) and during a submaximal graded exercise test (visit 3). HRV variables that were not normally distributed were log transformed before statistical analysis. Independent samples t-tests were used to establish differences between groups. Pearson correlations were calculated to determine relationships between OSA and HRV in terms of age and BMI. If there was a significant correlation between variables and age and/or BMI, then a repeated measures ANCOVA was used with age or BMI as the covariate. If there was not a significant correlation, a repeated measures ANOVA was utilized.

Results At rest, the OSA group had lower SDNN, RMSSD, and Total Power $(\mathrm{p}<0.05)$. A higher LF-HF ratio was found in the control group than the OSA group during exercise $(p<0.05)$. LFnu and HFnu were trending towards significance, both higher in the OSA group ( $\mathrm{p}=0.066$ and $\mathrm{p}=0.075$, respectively) during exercise indicating that the OSA group did not experience parasympathetic withdrawal. All subjects participate in about 30 minutes of moderate physical activity daily.
\end{abstract}


Discussion Results suggest that the OSA population may have increased autonomic dysfunction during exercise due to sympathetic dominance and a blunted parasympathetic response during steady-state exercise. Potential mechanisms for autonomic imbalances include decreased chemoreceptor and baroreceptor sensitivity. Further research with a larger OSA sample group is necessary. 


\section{Chapter 1 \\ Introduction}

Obstructive sleep apnea (OSA) is a sleep disordered breathing syndrome caused by the complete collapse of the pharyngeal airway. ${ }^{1,2}$ Apneas are pauses in respiration “associated with ongoing ventilatory effect" lasting at least ten seconds. ${ }^{1,3}$ Hypopneas are decreases in airflow combined with at least a 4 percent decrease in oxygen saturation due to a partial collapse of the pharyngeal airway. ${ }^{1}$ OSA affects about 3 to 7 percent of adult males and 2 to 5 percent of adult females, totaling 15 million adult Americans. ${ }^{1,4}$ In older adults over the age of 65 , the prevalence of OSA increases 2-3 fold compared to middleaged adults between the ages of 30-64 years old. ${ }^{5}$ Even though 15 million adult Americans have OSA, at least $85 \%$ of cases are undiagnosed. ${ }^{6}$ With the rise of obesity in America, the number of people with OSA is increasing. ${ }^{7}$ Roughly 1 in 5 adults has at least mild OSA and 1 in 15 adults have moderate or severe OSA. ${ }^{6}$

The severity of OSA is determined by the apnea-hypopnea index (AHI) which is measured by the number of apneas or hypopneas (also known as an "event") per hour of sleep. ${ }^{2}$ According to the AHI scale: mild OSA is 5 to 15 events per hour, moderate OSA is 15 to 30 events per hour, and severe OSA is greater than 30 events per hour. ${ }^{2}$ One is diagnosed with OSA when he/she has at least five events per hour combined with excessive daytime sleepiness. ${ }^{1}$ The most absolute way to diagnose OSA is the polysomnography method. This method requires the patient to participate in an overnight sleep study. ${ }^{6,8}$ The variables monitored and measured include the electroencephalogram, electromyogram, electrocardiogram, snoring, and respiration-flow, effort, and oxygen saturation. ${ }^{6}$ These variables yield the distribution of sleep states and severity of sleep- 
disordered breathing. ${ }^{9}$ Since polysomnography is an expensive method to detect OSA, heart rate variability has been used to assesses autonomic function. ${ }^{6}$

Numerous studies have established known risk factors for developing OSA. The most important and controllable risk factor is obesity. ${ }^{2,3,7,10}$ In the four-year follow-up Wisconsin Sleep Cohort Study, it was found that a 10 percent increase in weight yielded a six-fold increase in risk of developing OSA. ${ }^{5}$ Approximately 70 percent of people with sleep apnea are also obese. ${ }^{3}$ Other risk factors include male gender, large neck circumference, increased waist circumference and central body fat, and habitual snoring. ${ }^{1,5,11}$ However, it should be noted that not everyone with OSA is male, obese, tired, middle-aged, and snores. ${ }^{5}$ Anatomical risk factors include hypertrophic tonsils, high modified Mallampati grade, narrowing of palate or oropharyngeal walls, mandibular retrognathia ("overbite"), and small crico-mental space. ${ }^{11}$ Mallampati grade is a test that examines what is visible when a subject opens their mouth. For example, whether or not the tonsils, soft palate, and uvula are visible; if a subject receives a higher score, they are more likely to experience airway obstruction. ${ }^{12}$ Crico-mental space is determined "using a thin ruler to connect the cricoid cartilage to inner mentum. This line is then bisected and the perpendicular distance to the skin of neck is measured." ${ }^{\prime 13}$ There is also inconclusive evidence that genetics, smoking, menopause, alcohol use before sleep, and nighttime nasal congestion increase the risk of developing OSA. ${ }^{5}$

Common symptoms of people who develop OSA include loud and habitual disruptive snoring, breathing pauses during sleep, unwarranted daytime sleepiness, sexual dysfunction, and nocturnal choking and gasping. ${ }^{1,5}$ These symptoms have been related to a rise in vehicular crashes, psychosocial problems, decreases in cognitive function, and a 
decrease in quality of life. ${ }^{5}$ Sleep apnea has also been linked to various cardiovascular diseases including but not limited to hypertension, coronary artery disease, myocardial infarction, congestive heart failure, and stroke. ${ }^{5}$ In addition, there have been associations between OSA and diabetes and metabolic syndrome. ${ }^{2,5}$

The pathophysiology of OSA is complex and varies among patients. The most common causes are deficient pharyngeal anatomy and unsteady upper airway dilator muscle control while awake and asleep. ${ }^{1,3,14}$ When a person is awake, the upper airway dilator muscles are activated and used for speech, breathing, and swallowing. During sleep, the dilator muscles relax and are more likely to collapse. ${ }^{15}$ The collapsing of the airway can be attributed to negative pressure in the airway and positive pressure outside the airway. ${ }^{3}$ A study by Isono et al. found that patients with sleep apnea had smaller pharyngeal airways and increased collapsibility compared to the control group. ${ }^{16}$ Increased negative intraluminal pressure and narrowing of the pharyngeal airway has also been found to contribute to this pathophysiology. ${ }^{11}$ Another mechanism of OSA is the nocturnal loss of lung volume that decreases the traction on the upper airway increasing the collapsibility. ${ }^{1,17}$ This is caused by the excess fat around on the neck. Localized fat around the neck may also contribute to increased metabolic demand and amplified breathing effort. ${ }^{17}$ The lack of stability of the ventilatory control system may also cause OSA by the partial or complete collapse of the pharyngeal airway. ${ }^{1}$ OSA pathophysiology could derive from changing surface tension in the airway, arousal threshold, and asynchronous timing of activation of upper airway compared to pump muscles. ${ }^{1}$ The pathophysiology of OSA results in sympathetic overdrive impacting the 
autonomic nervous system. ${ }^{18}$ The decrease in autonomic function can be measured by heart rate variability.

Obstructive sleep apnea is related to cardiovascular diseases. More specifically, in patients with hypertension OSA is 30 to 83 percent higher, 12 to 53 percent higher in those with heart failure, 30 to 58 percent higher in those with ischemic heart diseases, and 43 to 91 percent higher in patients who have had a stroke. ${ }^{19}$ OSA and cardiovascular disease (CVD) do not necessarily have a causal relationship. However, OSA may hasten the rate of progression of any CVD including hypertension. In a four-year follow up study of the Wisconsin Sleep Cohort Study, researchers found a dose-response relationship between sleep apnea and the occurrence of hypertension four years later. ${ }^{20,21}$ The vasoconstriction in the periphery is a result of an apnea. When the person is able to breathe again, there is increased venous return and cardiac output against the vasoconstricted periphery which causes a rise in blood pressure. It has been documented that person without hypertension can reach up to $250 / 110 \mathrm{mmHg}$ after an apnea. ${ }^{18}$ There are numerous potential mechanisms that attribute OSA affecting CVD: vascular injury, acceleration of atherosclerosis due to hypoxemia, chronic sympathetic hyperactivity, hypertension, heart failure. ${ }^{14}$ The American Heart Association (AHA) proposes the following potential mechanisms: sympathetic activation, cardiovascular variability, vasoactive substances, inflammation, oxidative stress, endothelial dysfunction, insulin resistance, thrombosis, and intrathoracic pressure. ${ }^{1}$

OSA causes a lack of oxygen in the body when one has an event which causes autonomic dysfunction. Two primary mechanisms that cause this imbalance in the autonomic nervous system include decreased baroreceptor sensitivity and increased 
chemoreceptor sensitivity. Baroreceptors detect changes in blood pressure and aim to keep it within a normal range. When people with OSA experience hypoxia throughout the night, blood pressure rises. This reoccurring cycle desensitizes the baroreceptors which results in raising the detection level in which they perceive high blood pressure. ${ }^{22}$ As this level increases, the baroreceptors are more tolerant of higher blood pressures that they once detected increasing the likelihood of hypertension in this population. ${ }^{22}$ Higher blood pressure increases sympathetic activity causing an imbalance in the autonomic nervous system. During hypoxia, chemoreceptors detect lack of oxygen and increased carbon dioxide. This heightens the sympathetic nervous system resulting in increased heart rate and breathing and vasoconstriction thereby increasing blood pressure. ${ }^{23}$ Reoccurring hypoxias increase the sensitivity of the chemoreceptors ultimately increasing the initiation of sympathetic nervous system when oxygen desaturation is detected. ${ }^{23}$ Patients with OSA have decreased heart rate variability (HRV) and increased blood pressure variability. The decreased heart rate variability is potentially the connecting factor between OSA and CVD. ${ }^{1}$

HRV is the physiologic changing of the heart rate over time based on the interaction between the sympathetic and parasympathetic nervous systems which measures autonomic function. ${ }^{4,24}$ It is measured by the changes in variation from R-R intervals and is caused by heart rate, blood pressure, and respiration rate. ${ }^{18,24-26} \mathrm{HRV}$ is influenced by the changes in the autonomic nervous system, caused by both internal and external stimuli, on the sinoatrial node. Measuring autonomic nerve function within the cardiovascular system can be done by monitoring HRV. ${ }^{4}$ In persons with OSA a decrease in HRV is believed to represent a decrease in autonomic control. ${ }^{27}$ Abnormal adaptability 
in autonomic nerve function is detected by decreased HRV and may be associated with diseases such as renal failure, liver insufficiency, diabetes, congestive heart failure, and myocardial infarction. ${ }^{4}$ Narkiewicz et al evaluated cardiovascular variability in OSA patients without CVD. The patients were divided into 3 groups: mild OSA, moderate to severe OSA, and a control group. It was found that patients with moderate to severe OSA had significantly shorter RR intervals, faster heart rate, increased sympathetic burst frequency, and changing blood pressure. ${ }^{18}$ They concluded that "cardiovascular variability is altered in patients with OSA, even in the absence of hypertension, heart failure, or other disease states; and the degree of derangement in cardiovascular variability may be linked to the severity of OSA." 18

HRV can be analyzed using time-domain and frequency-domain measures. ${ }^{28}$ Time-domain measures include the standard deviation of all NN or RR intervals (SDNN), the square root of the mean of the sum of squares of differences between adjacent $\mathrm{NN}$ or RR intervals (RMSSD), and the division of the number of interval differences of successive $\mathrm{NN}$ intervals greater than $50 \mathrm{~ms}$ by the total number of $\mathrm{NN}$ intervals (pNN50). ${ }^{29-31}$ SDNN represents all cyclic components of variability. ${ }^{29-31}$ RMSSD is the estimate of all short term components of HRV. ${ }^{29-31}$ Frequency-domain measures include total power, low frequency (LF), high frequency (HF), and the LF-HF ratio. The total power is the variance of $\mathrm{NN}$ intervals over the time period analyzed. ${ }^{31}$ The HRV spectrum is comprised of two parts: a LF band and a HF band. The HF band (0.15-0.4 $\mathrm{Hz}$ ) represents the parasympathetic system; the LF band $(0.04-0.15 \mathrm{~Hz})$ is related to both the parasympathetic and sympathetic systems. ${ }^{32}$ In a recent study, researchers compared HRV between OSA patients and control subjects using data collected from 
electrocardiogram. The researchers found a higher LF power, a lower HF power, and a higher LF-HF ratio in OSA patients compared to the control subjects. ${ }^{28}$ This supports the evidence increased sympathetic activity and/or decreased parasympathetic activity in people with OSA. ${ }^{28}$ In patients with OSA, a decrease in HRV has been found but there is variance in the HRV among patients suffering from OSA. The HRV pattern may be different depending on gender, obesity, OSA severity, duration of sleep, and oxygen saturation levels. $^{25}$

Many studies have evaluated the relationship between OSA and HRV. A study of 78 patients with suspected OSA participated in an overnight polysomnography in which HRV was also measured. Those with severe OSA had an increased number of longer accelerated beats and a decreased number of deceleration beats indicating the lack of balance between accelerations and decelerations in heart rate. ${ }^{33}$ An increase in cardiac sympathetic drive is seen in patients with OSA during resting wakefulness depicted by faster heart rates. ${ }^{1}$ There is also an increase in the activity of the parasympathetic nervous system in OSA patients during sleep which suggests that it is related to mechanisms compensating oxygen saturation changes. ${ }^{25}$ In another study, it was found that patients with severe OSA had a shorter R-R interval during the night. ${ }^{24}$ OSA and blunted HRV are both risk factors for cardiovascular disease which may cause mortality. ${ }^{27}$ In comparison to similar obese control subjects, awake OSA patients at rest have decreased HRV and increased blood pressure variability. ${ }^{1}$ Unfavorable outcomes are expected in those with cardiovascular disease and diminished HRV. ${ }^{1}$ According to the Framingham Heart Study, lower HRV is a risk factor to the development of hypertension and increased blood pressure variability has been associated with a higher 
risk of organ damage in those with cardiovascular disease. ${ }^{1}$ In the Wisconsin Sleep Study, a relationship between OSA and hypertension was confirmed. ${ }^{2}$ OSA patients are more likely to develop coronary artery disease, cerebrovascular disease, atherosclerosis, arterial stiffness, cardiac arrhythmias, and heart failure. ${ }^{2}$

It is still unknown as to whether or not OSA limits exercise capacity. It can be assumed that because people with OSA have increased daytime sleepiness, there would be a decreased desire to engage in physical activity and are more exhausted at a given workload. ${ }^{34}$ The combination of unwarranted daytime sleepiness and fatigue could potentially impact the difficulty of exercise for people with OSA. Levels of fatigue may be increased at lower intensity exercise due to the overloading of dilator muscles after an apnea occurs. ${ }^{35}$ Studies have observed the impact that exercise training has on the severity of OSA. A meta-analysis by Iftikhar et al. examined the effectiveness of exercise training in OSA patients in terms of severity, BMI, sleep efficiency, daytime sleepiness, and cardiovascular fitness. ${ }^{36}$ Interestingly, the researchers found that despite changes in BMI and body weight, exercise does have a significant effect on AHI. ${ }^{36}$ Exercise training was able to decrease the severity of the patients' OSA.

As previously mentioned, OSA increases the risk for developing CVD including faster heart rate, longer heart rate recovery period, longer QT-interval, and longer P-wave duration. ${ }^{37}$ Longer P-wave and QT-interval durations increase the likelihood of an abnormal heart rhythm. There is a four-fold increase for atrial fibrillation if a patient has severe OSA at rest. ${ }^{37}$ The question then arises whether or not exercise is safe for people with OSA. During exercise there is a higher risk for experiencing an abnormal heart rate or rhythm. Exercise increases sympathetic activity and number of circulating 
catecholamines potentially causing increased abnormal automaticities and related premature beats. $^{38}$ Arrhythmias are also common in people with OSA. For example, the risk for ventricular tachycardia, second degree atrioventricular block, and premature ventricular contractions is higher in the OSA population. ${ }^{39,40}$ An increased resting heart rate and cardiovascular events have shown to be associated in many studies although "few studies have looked at the impact of OSA on HR." 37 Investigating this impact will give greater insight into how the autonomic nervous system responds to exercise when it is altered because of OSA. It is unknown whether acute exercise would increase the likelihood of a patient with untreated OSA to have abnormal heart rhythms and if exercise would be safe for this population.

\section{Purpose:}

This study analyzed HRV at rest and during submaximal exercise in OSA patients and a control group.

\section{Hypothesis:}

We hypothesized that during exercise, autonomic function measured via HRV would be blunted in OSA patients as compared to a control group.

\section{Limitations:}

Subjects often overestimated or underestimated their physical activity levels.

\section{Delimitations:}

Subjects had a body mass index of at least $25 \mathrm{~kg} / \mathrm{m}^{2}$. 
Subjects who were using medications that may influence heart rate were excluded from this study.

Subjects did not have any cardiovascular, pulmonary, or metabolic diseases. 


\section{Chapter 2 \\ Methodology}

\section{Participants}

The researchers recruited twenty persons with obstructive sleep apnea (OSA) from James Madison University and the Rockingham Memorial Hospital Center for Sleep Medicine in Harrisonburg, Virginia. In addition, a non-OSA control group was recruited. Inclusion criteria for subjects included males and females at least eighteen years old with a minimum BMI of $25 \mathrm{~kg} / \mathrm{m}^{2}$. Exclusion criteria for subjects included known cardiovascular disease, congestive heart failure, or pulmonary disease, and being in the "high risk for atherosclerotic cardiovascular disease" category as defined by the American College of Sports Medicine. ${ }^{41}$ The International Physical Activity Questionnaire Short Form (IPAQ) was used to exclude those who were highly physically active in order to eliminate the potential influence of regular physical activity on the study's outcomes. Any persons taking medications that could potentially influence heart rate and HRV were also excluded. Participants were asked to report to the Human Performance Laboratory (HPL) in Godwin Hall at James Madison University on three separate occasions for a total of two and a half hours. All procedures were approved by the JMU Institutional Review Board (IRB).

\section{$\underline{\text { Visit } 1}$}

Before the testing began, all subjects completed a health history questionnaire (HHQ) in order to provide basic health information and to identify any potential exclusion criteria as well as three additional questionnaires. The Berlin Questionnaire (BQ) and the Screening Tool for OSA (STOP) Questionnaire were used to establish risk 
factors for OSA and their level of snoring, and the Epworth Sleepiness Scale (ESS) was used to establish daytime sleepiness levels.

\section{Body Mass and Height}

Subjects had their body weight and height measured using a physician's scale and stadiometer, respectively. The subjects removed their shoes, excess/layered clothing, and any items in their pockets before stepping on to the scale. Body weight was measured to the nearest $0.5 \mathrm{lbs}$ and converted to kilograms. Height was measured with a stadiometer to the nearest $0.5 \mathrm{~cm}$. Waist and neck circumferences measurements were taken using a cloth tape measure with a spring-loaded handle to reduce the compression of the skin. The waist circumference was measured directly above the subject's iliac crest. The neck circumference was measured around the widest part of the subject's neck.

\section{Anthropometry and Body Composition}

Body composition was analyzed using a Dual-Energy X-Ray Absorptiometer (Lunar iDXA 1RME+200072 (14.10), Madison, Wisconsin). The scan consists of total body/visceral fat and bone mineral density. The subject was symmetrically centered within the white outer lines on the bed with their spine and head along the center line. If the subject could not fit within the white box, he or she was adjusted so that their entire right side fit within the box. The DEXA is capable of estimating total body fat based on a scan of one side of the body. 


\section{At-Home Sleep Assessment}

The ApneaLink ${ }^{\mathrm{TM}}$ (ApneaLink ${ }^{\mathrm{TM}}$ Plus, San Diego, California) was used to screen for the presence of OSA. The research staff thoroughly explaind to the participants how to setup and use the ApneaLink ${ }^{\mathrm{TM}}$ at-home screening device. When subjects returned the ApneaLink $^{\mathrm{TM}}$ the following day, the data collected by the device was downloaded using the ApneaLink ${ }^{\mathrm{TM}}$ software. The software analyzed the number of events per hour the subject had as well as the amount of snoring, oxygen saturation levels, and sleep latency. A certified sleep technician and sleep physician reviewed the sleep data collected by the ApneaLink $^{\mathrm{TM}}$. In addition, subjects were given an accelerometer (ActiGraph, GT3XPlus, Pensacola, Florida) to assess nocturnal movement. The ActiGraph is a small device worn on their non-dominant wrist during sleep and was attached to a watch in order to prevent insignificant movement of the accelerometer. Participants were instructed to record the times that they went to bed and the time they got out of bed on a log sheet and to note any abnormalities that may have occurred during sleep. The ActiGraph was worn for 4 days including 3 weekdays and 1 weekend day.

\section{Physical Activity Assessment}

The ActiGraph accelerometer was also utilized to assess the subjects' daily physical activity levels. Subjects wore the accelerometer on the waistband of their right waist line mid-thigh. Subjects were asked to continue their normal daily activities and to document any abnormal physical activities. After the four days of physical activity assessment, subjects returned the accelerometer device to the HPL, and continued with Visit 3 procedures. 


\section{$\underline{\text { Visit } 2}$}

\section{Heart Rate Variability Assessment}

Each subject completed HRV measurements, heart rate, and blood pressure measurements at rest. Heart rate and HRV were measured using a Polar RS800CX monitor (Kempele, Finland). The monitor's data was saved to the Polar watch which was downloaded using the Polar Pro Training 5 software. Subjects laid supine in a darkened room while the heart rate and HRV were monitored over a 15 minute time period. In addition, resting hemodynamic values was assessed using a non-invasive bioimpedance device (PhysioFlow FP-05 Lab 1, NeuMeDx, Bristol, Pennsylvania). Subjects were asked to breathe in synchronization with a metronome at 12 beats per minute to control for the effect of respiration on the HRV variables.

The HRV variables are based on frequency or time-domain. Frequency based variables include total power (TP), LF, HF, and LF-HF ratio. TP $\left(\mathrm{msec}^{2}\right)$ measures the energy in the heart from 0 to $.40 \mathrm{~Hz} .^{42} \mathrm{LF}\left(\mathrm{msec}^{2}\right)$ is the energy in the heart from 0.04 to $0.15 \mathrm{~Hz}$. There is numerous controversial research stating that LF does not solely represent sympathetic activity but also represents parasympathetic drive. ${ }^{29,30}$ According to Massimo Pagani's research group, the LF component shows cardiac sympathetic flow. ${ }^{30} \mathrm{HF}\left(\mathrm{msec}^{2}\right)$ is the energy in the heart from 0.15 to $0.40 \mathrm{~Hz}$ and represents parasympathetic activity. Malliani, Lombardi, and Pagani found in healthy human subjects and animal experiments, the LF factor of heart rate and arterial pressure variability was increased by moderate hypotension, physical activity, and the occlusion of the coronary or carotid arteries. ${ }^{43}$ The increase in the LF factor was accompanied by a 
decrease in the HF factor. The HF factor of HRV was increased in humans by controlled respiration, cold stimulation of the face, and rotational stimuli. ${ }^{43}$ The LF-HF ratio is simply the ratio between the LF and the HF power and reflects sympathovagal balance. ${ }^{42}$ The ratio also shows the relative sympathetic input of the control of one's heart rate. ${ }^{30}$ The time domain variables include pNN50, SDNN, and rMSSD. pNN50 is a percentage of differences between consecutive R-R intervals greater than $50 \mathrm{msec}$. SDNN (msec) is the standard deviation of all normal R-R intervals during the recording and is related to total power. rMSSD (msec) is the square root of the mean of the squares of differences between consecutive R-R intervals and reveals parasympathetic activity. ${ }^{42}$

Resting Blood Pressure

Seated blood pressure was measured after the resting HRV assessment via auscultation.

$\underline{\text { Visit } 3}$

Submaximal Exercise Test

Subjects completed a two-stage, sub-maximal graded exercise test on the treadmill. Before the exercise test, maximal fitness level $\left(\mathrm{VO}_{2 \max }\right)$ was predicted using a validated regression equation based on age, gender, physical activity status, and BMI. ${ }^{42}$ The treadmill speed was set to 3.5 miles per hour; the incline was individually adjusted based on predicted $\mathrm{VO}_{2}$ max corresponding to a light intensity $\left(35 \% \mathrm{VO}_{2}\right.$ reserve $\left.{ }^{41}\right)$ and a vigorous intensity $\left(70 \% \mathrm{VO}_{2}\right.$ reserve $\left.{ }^{41}\right)$. Subjects walked for a period of five minutes at each intensity level. Heart rate and HRV were continuously monitored throughout the exercise test and recovery with the Polar RS800CX monitor. Blood pressure was also 
monitored at each stage and during exercise recovery. Similar to resting hemodynamic values obtained during visit 2 , cardiovascular hemodynamic variables were obtained throughout exercise and recovery using the PhysioFlow and a Metabolic Cart (Parvo Medics True One 2400 Metabolic Measurement System, Sandy, Utah). Exercise tests were terminated if subjects reach $85 \%$ of their predicted maximal heart rate reserve in accordance with the published ACSM guidelines for sub-maximal exercise tests. ${ }^{41}$ The test was also terminated if any subjects had contraindications during the exercise test published in the ACSM guidelines. ${ }^{41,44}$

\section{$\underline{\text { Statistics }}$}

Statistical analysis was performed using SPSS. Subject characteristics were reported as means \pm standard deviation. Statistical significance was set at $p<0.05$. HRV variables that were not normally distributed were log transformed before statistical analysis. Normalized LF (LFnu) was calculated as LFnu $=$ LF/(TP-VLF)*100 and normalized HF (HFnu) was calculated as HFnu = HF/(TP-VLF)*100. Independent samples t-tests were utilized to identify baseline differences between the OSA group and control group. Pearson correlations were calculated to determine relationships between age and BMI. If a significant effect of age or BMI was observed, then an analysis of covariance (ANCOVA) was used with an adjustment. If the effect of age or BMI was not significant, then a repeated measures analysis of variance (ANOVA) was used without adjustment. 


\title{
Chapter 3 \\ Manuscript
}

\section{The Effects of Obstructive Sleep Apnea (OSA) on Autonomic Function during Steady-State Exercise}

\begin{abstract}
Purpose The aim of this study is to assess autonomic function by analyzing heart rate variability (HRV) at rest and during submaximal exercise in OSA patients and a nonOSA control group.

Methods Subjects were classified as OSA $(\mathrm{n}=10)$ or non-OSA $(\mathrm{n}=16)$ based on results from an at-home sleep assessment. Height, weight, waist and neck circumferences, and body composition were collected during the first visit for each subject. Physical activity during the day and nocturnal movement were assessed over a period of 4 days, including 3 weekdays and 1 weekend day, using accelerometers. HRV and blood pressure were recorded at rest (visit 2) and during a submaximal graded exercise test (visit 3). HRV variables that were not normally distributed were log transformed before statistical analysis. Independent samples t-tests were used to establish differences between groups. Pearson correlations were calculated to determine relationships between OSA and HRV in terms of age and BMI. If there was a significant correlation between variables and age and/or BMI, then a repeated measures ANCOVA was used with age or BMI as the covariate. If there was not a significant correlation, a repeated measures ANOVA was utilized.

Results At rest, the OSA group had lower SDNN, RMSSD, and Total Power $(\mathrm{p}<0.05)$. A higher LF-HF ratio was found in the control group than the OSA group during exercise ( $\mathrm{p}<0.05)$. LFnu and HFnu were trending towards significance, both higher in the OSA
\end{abstract}


group ( $\mathrm{p}=0.066$ and $\mathrm{p}=0.075$, respectively) during exercise indicating that the OSA group did not experience parasympathetic withdrawal. All subjects participate in about 30 minutes of moderate physical activity daily.

Discussion Results suggest that the OSA population may have increased autonomic dysfunction during exercise due to sympathetic dominance and a blunted parasympathetic response during steady-state exercise. Potential mechanisms for autonomic imbalances include decreased chemoreceptor and baroreceptor sensitivity. Further research with a larger OSA sample group is necessary. 


\section{Introduction}

Obstructive sleep apnea (OSA) is a sleep disorder characterized by the partial and/or complete collapse of the pharyngeal airway in addition to excessive daytime sleepiness. ${ }^{1,2}$ An apnea occurs when there is a total collapse of the pharyngeal airway lasting at least ten seconds. ${ }^{1,3}$ A partial collapse airway combined with at least a 4 percent decrease in oxygen saturation is referred to as a hypopnea. ${ }^{1}$ OSA affects approximately 15 million adult Americans ${ }^{1,4}$; however, it is estimated that at least $85 \%$ of cases are undiagnosed. ${ }^{5}$ In adults over the age of 65 , the prevalence increases two-tothree fold compared to adults between the ages of 30-64 years old. ${ }^{6}$ With the rise of obesity in America, the number of people with OSA is likely increasing. ${ }^{7}$ This disorder has been found to be related to a rise in vehicular crashes, psychosocial problems, decreases in cognitive function, and a decrease in quality of life. ${ }^{6}$ This syndrome has also been linked to various cardiovascular diseases such as hypertension, coronary artery disease, myocardial infarction, congestive heart failure, and stroke. ${ }^{6}$

The most common and controllable risk factor for OSA is obesity. ${ }^{2,3,7,8}$ Roughly $70 \%$ of people with sleep apnea are also obese. ${ }^{3}$ Other risk factors include male gender, large neck circumference, increased waist circumference, habitual snoring, and upper airway structural abnormalities. ${ }^{1,6,9}$ Structural abnormalities include enlarged tonsils, narrowing of palate or oropharyngeal walls, and mandibular retrognathia. ${ }^{9}$ There is inconclusive evidence that genetics, smoking, menopause, alcohol use before sleep, and nighttime nasal congestion increase the risk for developing OSA. ${ }^{6}$

The pathophysiology of OSA is complex and varies among patients. The most common causes of are deficient pharyngeal anatomy and unsteady upper airway dilator 
muscle control while awake and asleep. ${ }^{1,3,10}$ During wakefulness, a person is in control of their dilator muscles as they are used for speech, breathing, and swallowing. During sleep, the dilator muscles relax and are more likely to collapse. ${ }^{11}$

The pathophysiology mechanisms of OSA result in sympathetic overdrive impacting the autonomic nervous system. ${ }^{12}$ Two potential mechanisms that cause this imbalance in the autonomic nervous system include decreased baroreceptor sensitivity and increased chemoreceptor sensitivity. Baroreceptors detect changes in blood pressure and aim to keep it within a normal range. When people with OSA experience hypoxia throughout the night, blood pressure rises. This reoccurring cycle desensitizes the baroreceptors which results in raising the "set point" or level in which they detect the high blood pressure. ${ }^{13}$ As this level increases, the baroreceptors are less sensitive to the higher blood pressures. ${ }^{13}$ When the baroreceptors become desensitized, a rise in blood pressure is not countered by a reduction in sympathetic activity, thereby contributing to an autonomic imbalance. During hypoxia, chemoreceptors detect lack of oxygen and increased carbon dioxide. This heightens the sympathetic nervous system resulting in increased heart rate, breathing, and vasoconstriction thereby increasing blood pressure. ${ }^{14}$ Reoccurring hypoxias increase the sensitivity of the chemoreceptors ultimately increasing the initiation of sympathetic nervous system when oxygen desaturation is detected. ${ }^{14}$ Additionally, patients with OSA also have faster heart rates while awake, potentially signifying a heightened sympathetic nervous system. ${ }^{1}$ The aroused sympathetic nervous system in people with sleep apnea creates an imbalance in the autonomic nervous system, specifically between the sympathetic and parasympathetic nervous systems. The decrease in autonomic function can be measured by heart rate variability (HRV). 
$\mathrm{HRV}$ is the physiologic changing of the heart rate over time based on the interaction between the sympathetic and parasympathetic nervous system. ${ }^{4,15}$ It is measured by the changes in variation from R-R (also known as N-N) intervals and is caused by heart rate, blood pressure, and respiration rate. ${ }^{12,15-17}$ A decrease in autonomic control may be associated with diseases such as renal failure, liver insufficiency, diabetes, congestive heart failure, and myocardial infarction. ${ }^{4}$ Patients with moderate to severe OSA have significantly shorter R-R intervals, faster heart rate, increased sympathetic burst frequency, and changing blood pressure. ${ }^{1,12,15}$

Although the relationship between OSA and HRV has been studied in both awake and asleep patients at rest, the relationship has not been examined during a bout of acute exercise. Previous research has investigated autonomic function during exercise in untreated OSA subjects measured by heart rate and blood pressure recovery. ${ }^{18}$ The study found a decreased heart rate response in the OSA group during the recovery period suggesting autonomic dysfunction. ${ }^{18}$ Other studies have similarly found a decreased or blunted response in heart rate recovery after a bout of exercise. ${ }^{19-21}$

It is also known that during exercise there is a higher risk for experiencing an abnormal heart rate or rhythm. Exercise increases sympathetic activity and number of circulating catecholamines potentially causing increased automaticities and related premature beats. $^{22}$ Arrhythmias are also common in people with OSA. For example, there is a four-fold increase for atrial fibrillation if a patient has severe $\operatorname{OSA}^{23}$ and the risk for ventricular tachycardia, second degree atrioventricular block, and premature ventricular contractions is higher in the OSA population. ${ }^{24-26,27,28}$ The question then arises whether or not exercise is safe for people with OSA. An increased resting heart 
rate and cardiovascular events have shown to be associated in many studies although "few studies have looked at the impact of OSA on HR." 23 Investigating this impact will give greater insight into how the autonomic nervous system, measured directly by HRV, responds during an exercise session when it is altered because of OSA. To date, no one has utilized HRV variables during exercise to further consider the autonomic dysfunction in OSA patients. It is unknown whether acute exercise would increase the likelihood of a patient with untreated OSA to have abnormal heart rhythms and if exercise would be safe for this population. Therefore, the purpose of this study is to analyze HRV at rest and during submaximal exercise of OSA patients and a control group.

\section{Methods}

\section{Participants}

Twenty-six (26) people from the Harrisonburg, Virginia community, including James Madison University (JMU) and the Sentara Rockingham Memorial Hospital $(\mathrm{RMH})$ Center for Sleep Medicine, were recruited for this study. Subjects were all at least 18 years old with at least a BMI of $25 \mathrm{~kg} / \mathrm{m}^{2}$. Exclusion criteria included known cardiovascular disease, congestive heart failure, or pulmonary disease, and being in the "high risk for atherosclerotic cardiovascular disease" category as defined by the American College of Sports Medicine (ACSM). ${ }^{29}$ Any persons taking medications that could potentially influence heart rate and HRV were also excluded. Highly active individuals ( $\geq 3$ days of endurance exercise) and people who have received treatment for OSA were excluded from the study. Subjects were asked to report to the Human Performance Laboratory at James Madison University on three separate occasions within 
a one week time period. All procedures have been approved by the JMU and Sentara RMH Institutional Review Boards.

$\underline{\text { Visit } 1}$

Questionnaires

Before testing began, all subjects completed the consent form and several questionnaires. Subjects completed a health history questionnaire to establish risk factors described in the ACSM guidelines. ${ }^{29}$ The Berlin Questionnaire and the Screening Tool for OSA (STOP) Questionnaire were used to establish risk factors for OSA and their level of snoring. The Epwoth Sleepiness Scale (ESS) determined their level of daytime sleepiness. The International Physical Activity Questionnaire Short Form was used to establish a baseline for each subject's physical activity level.

\section{Anthropometry and Body Composition}

All subjects had their body weight using a physician's scale and height measured using a stadiometer. Body weight was recorded to the nearest $0.1 \mathrm{lbs}$ and converted to kilograms; height was recorded to the nearest $0.25 \mathrm{~cm}$. Waist, hip, and neck circumferences were measured and followed the procedures described in the ACSM guidelines. ${ }^{29}$ Measures of total and regional body composition were measured using a dual-energy a-ray absorptiometer (Lunar iDEXA 1 RME+200072 (14.10), Madison, Wisconsin).

\section{At-Home Sleep Assessment}

Subjects wore the ApneaLink ${ }^{\mathrm{TM}}$ (ApneaLink $^{\mathrm{TM}}$ Plus, San Diego, California) for one night in order to screen for the possible presence of OSA. Data collected from the 
ApneaLink $^{\mathrm{TM}}$ include the AHI, snoring patterns, oxygen saturation levels, sleep latency, apneas, and hypopneas. The OSA group had an AHI $\geq 5$; the control group had an AHI $<$ 5. Subjects also wore a wrist accelerometer (ActiGraph, GT3X-Plus, Pensacola, Florida) for 4 nights (3 weeknights and 1 weekend night) on their non-dominant wrist to assess nocturnal movement. Participants recorded the times that they went to bed and the time they got out of bed on a log sheet and to note any abnormalities that may have occurred during sleep.

Physical Activity Assessment

An accelerometer was worn on each subject's waistband of their right waist line mid-thigh for 4 days ( 3 weekdays and 1 weekend day). Subjects reported anytime they did not wear the device, planned bouts of exercise, and any abnormal physical activities. The accelerometer measures activity based on movement counts per minute. ${ }^{30}$ The number of movement counts per minute determines the subject's intensity. The amount of time spent at the various intensity levels is reported in table 2. Variables measured from the accelerometer include the following: the number of sedentary bouts and the duration of each bout; the amount of time spent being sedentary, participating in light, lifestyle, moderate, vigorous, and very vigorous physical activity; and the number of steps per day.

\section{$\underline{\text { Visit } 2}$}

Heart Rate Variability Assessment

Heart rate and HRV were measured using a Polar RS800CX monitor (Kempele, Finland). The monitor's data was saved to the Polar watch which was downloaded using the Polar Pro Training 5 software. Subjects were asked to lie supine in a darkened room 
while the heart rate and HRV were monitored over a 15 minute time period. In addition, each subject's resting blood pressure was measured according to the ACSM procedures. ${ }^{29}$ Subjects were asked breathe in synchronization with a metronome at 12 beats per minute to control for the effect of respiration on the HRV variables.

The HRV variables are based on frequency or time-domain. Frequency based variables include total power, low frequency $(\mathrm{LF})$, high frequency $(\mathrm{HF})$, and LF-HF ratio. ${ }^{31}$ Total power is the variance of $\mathrm{NN}$ intervals over the time period analyzed (2 minutes for this study). ${ }^{32}$ The LF and HF bands form the HRV spectrum. The HF band (0.15-0.4 Hz) represents the parasympathetic system; the LF frequency band (0.04-0.15 $\mathrm{Hz}$ ) is associated with both the parasympathetic and sympathetic systems. ${ }^{33}$ There are three time domain variables. The first is the standard deviation of all the NN intervals $(\mathrm{SDNN}) .{ }^{32,34,35} \mathrm{rMSSD}$ is the square root of the mean of the sum of the squares of differences between adjacent $\mathrm{NN}$ intervals_-estimate of all short term components of HRV. $^{32,34,35}$ pNN50 is the division of NN50 (the number of interval differences of successive $\mathrm{NN}$ intervals greater than $50 \mathrm{~ms}$ ) by the total number of $\mathrm{NN}$ intervals. ${ }^{32,34,35}$

\section{$\underline{\text { Visit } 3}$}

Subjects completed a two-stage, submaximal graded exercise test on the treadmill. Before the exercise test, maximal fitness level $\left(\mathrm{VO}_{2 \max }\right)$ was predicted using a validated regression equation based on age, gender, physical activity status, and BMI. ${ }^{31}$ The treadmill speed was set to 3.5 miles per hour unless the subject could not tolerate this speed, then it was set to 3.0 miles per hour. The incline was individually adjusted based 
on the predicted $\mathrm{VO}_{2 \max }$ corresponding to a light intensity $\left(35 \% \mathrm{VO}_{2}\right.$ reserve $\left.{ }^{29}\right)$ and a vigorous intensity $\left(70 \% \mathrm{VO}_{2}\right.$ reserve $\left.^{29}\right)$.

Subjects walked for five minutes at each intensity while heart rate, HRV, blood pressure, and ratings of perceived exertion variables were obtained. Tests were terminated if any subjects had any contraindications during the exercise test as published in the ACSM guidelines. ${ }^{29,36}$

\section{Statistical Analysis}

Statistical analysis was performed using SPSS. Subject characteristics are reported as means \pm standard deviation. Statistical significance was set at $p<0.05$. HRV variables that were not normally distributed were log transformed before statistical analysis. Normalized LF (LFnu) was calculated as LFnu $=$ LF/(TP-VLF)*100 and normalized HF (HFnu) was calculated as HFnu $=\mathrm{HF} /(\mathrm{TP}-\mathrm{VLF}) * 100$. Independent samples t-tests were utilized to identify baseline differences between the OSA group and control group. Pearson correlations were calculated to determine relationships between age and BMI. If a significant effect of age or BMI was observed, then an analysis of covariance (ANCOVA) was used with an adjustment. If the effect of age or BMI was not significant, then a repeated measures analysis of variance (ANOVA) was used without adjustment.

\section{Results}

\section{Baseline Characteristics}

Twenty-six subjects were divided into two groups based on their AHI value. Subject characteristics are presented in Table 1. The OSA group was significantly older 
than the control group. In addition, the OSA group had a significantly larger BMI, neck circumference, and waist circumference. Sleep efficiency was significantly reduced in the OSA group $(\mathrm{p}=0.013)$; there were no differences in any other sleep quality variables (Table 3). BMI significantly correlated with average length of awakening $(\mathrm{r}=0.55, \mathrm{p}=$ 0.005). This was the only variable that significantly correlated with BMI; therefore no other variables were adjusted. There were no differences in physical activity between the OSA and control groups (Table 2). The subjects averaged 30 minutes of moderate

physical activity each day ( $30 \pm 16.8$ minutes $)$, thus meeting the ACSM guidelines. ${ }^{37}$ On average, all subjects participated in physical activity $5 \pm 0.71$ days/ week. No subjects engaged in very vigorous activity. Subjects walked $5481 \pm 2200$ steps/day.

\section{Oxygen Consumption}

There were significant differences between predicted oxygen consumption between the OSA and control groups $(\mathrm{p}<0.05)$ as seen in Table 4 which can be attributed to the age difference between groups. However, there were no differences between groups for oxygen consumption, respiratory exchange ratio (RER), and systolic blood pressure at either intensity (Table 4). There was a trend for diastolic blood pressure to be higher in the OSA group with exercise, but it did not reach statistical significance $(\mathrm{p}=0.067)$. Both groups had a significantly higher oxygen consumption $\left(\mathrm{VO}_{2}\right)$ at both intensities than predicted $\mathrm{VO}_{2}$ as seen in Table $4(\mathrm{p}<0.001)$.

\section{Heart Rate Variability}

Resting HRV data is shown in Table 5. SDNN, RMSSD, and TotalPower were significantly lower in the OSA group compared to the control group $(\mathrm{p}<0.05)$. There 
were no group differences in HF and LF. There was a significant main effect for age in both HF $(p=0.027)$ and LF $(p=0.041)$. An ANCOVA was used for HF and LF with age as the covariate.

Exercise HRV data is presented in Table 5. During exercise, there was a significant main effect for intensity, as SDNN and HF decreased as the intensity increased. There was no main effect for group. During exercise, there was a significant main effect for intensity, as RMSSD and LF increased as the intensity increased. There was no main effect for group. For LFnu and HFnu there was no main effect for intensity, but there a trend towards a main effect for group with the OSA group higher $(\mathrm{p}=0.066$ and $\mathrm{p}=0.075$ for LFnu and HFnu, respectively) (Figure 1A and 1B). There was no significant main effect for intensity for LF-HF ratio; however, there was a significant main effect for group. The OSA group had a significantly lower LF-HF ratio compared to the control group (Figure 1C).

\section{Discussion}

This study confirms the findings of previous research on the autonomic function of the OSA population at rest. During rest we saw lower values in SDNN, total power (TP), and RMSSD in the OSA group indicating overall decreased HRV in this population. SDNN represents a general picture of HRV, with a lower SDNN indicating a lack of balance between sympathetic and parasympathetic activity or an autonomic dysfunction $^{38}$ A lower SDNN further suggests that the body is unable to maintain homeostasis in the presence of internal and external stressors. ${ }^{39}$ A lower TP variable also shows a decrease in total HRV, again providing evidence of autonomic dysfunction in people with OSA. The OSA group also had lower RMSSD at rest indicating either vagal 
withdrawal, sympathetic dominance, or a combination of both. ${ }^{40}$ The autonomic dysfunction at rest in this population is seen by increased sympathetic activity and decreased parasympathetic activity. ${ }^{41}$ These resting HRV findings are in agreement with several studies. $^{41-44}$

A unique and major finding in our study was that during steady-state exercise HFnu (i.e. parasympathetic activity) in the OSA group did not change significantly between rest and exercise (Figure 1B). Moreover, the significant reduction in the LF-HF was at least partially attributable to the unchanged HFnu (Figure 1C). The initial increase from rest to light intensity in the LF-HF ratio during can be attributed to vagal withdrawal rather than sympathetic stimulation. ${ }^{45}$ The decrease in the ratio from light to vigorous intensity was expected since the balance between the sympathetic and parasympathetic systems decreases in proportion to the exercise intensity (Figure 1C). ${ }^{45}$ The OSA group had a significantly lower LF-HF ratio during exercise (Table 5, Figure 1C). The LF-HF ratio represents the balance between the sympathetic and parasympathetic systems. ${ }^{38}$ A higher LF-HF ratio would indicate increased sympathetic dominance, while a lower LF-HF ratio would indicate an increased parasympathetic dominance. $^{39}$ The lower LF-HF ratio in the OSA group could potentially be explained by the HFnu variable during steady-state exercise. The HFnu did not change between rest and vigorous intensity in the OSA group (Table 5, Figure 1B). In a normal, healthy individual during early exercise, there is vagal withdrawal and increased sympathetic activity ultimately increasing the individual's heart rate. ${ }^{45,46}$ As exercise duration continues and intensity increases, sympathetic activity also increases. ${ }^{45,46}$ In this study, as expected, the control group decreased HFnu with exercise due to vagal withdrawal and 
sympathetic excitation. Parasympathetic activity did not change significantly among the three conditions in the OSA group. The lack of parasympathetic withdrawal could be the link to autonomic dysfunction in this population.

During exercise, the OSA group was trending towards a higher main effect for group in terms of HFnu $(\mathrm{p}=0.075$, Table 5 , Figure $1 \mathrm{~B})$. This indicates a lack of parasympathetic response during exercise in the OSA group. Though the difference at rest is not statistically significant, it may suggest that people with OSA inherently have a lower level of parasympathetic activity. The OSA group was trending towards a significantly higher main effect for group in terms of LFnu ( $p=0.066$, Table 5, Figure 1A). This is in agreement with previous literature since people with OSA have sympathetic dominance. ${ }^{44}$ Alameri et al. attributed increases in blood pressure and heart rate and delayed return to resting heart rate in an OSA group during a 6 minute walk test to sympathetic overdrive and delayed parasympathetic activity. ${ }^{47}$ The increase in breathing frequency and tidal volume that occurs during exercise may have been accelerated in the OSA group which would result in higher HFnu values compared to the control group. ${ }^{48}$ The lack of parasympathetic withdrawal may cause the decreased HRV by not allowing the heart rate to vary as much during exercise. This could be the link to autonomic dysfunction in this population.

Potential mechanisms for the autonomic dysfunction in the OSA population include the decreased baroreceptor sensitivity and heightened chemoreceptor sensitivity. Baroreceptors are part of a homeostatic mechanism to keep blood pressure regulated. If blood pressure increases, the baroreceptors send signals to the brain to decrease sympathetic activity. This primarily slows down the heart and dilates the blood vessels 
ultimately allowing for the blood to flow through the vessels with less pressure. ${ }^{49}$ Repetitive hypoxias that occur in people with OSA cause increases in blood pressure. In the presence of hypoxias and constant blood pressure variability, the baroreceptors become desensitized to higher pressures. ${ }^{13,40}$ This decreased sensitivity in these receptors increases likelihood of increased sympathetic activity and hypertension in this population. ${ }^{14,50}$ Chemoreceptors are also very important in people with OSA since they detect decreases in oxygen saturation. ${ }^{51}$ When these receptors sense oxygen desaturation, the sympathetic nervous system is heightened and constricts vessels thereby increasing blood pressure. ${ }^{14,42,51-54}$ The actions of both baroreceptors and chemoreceptors cause increases in sympathetic activity and related autonomic dysfunction in people with OSA. ${ }^{13,14}$

One limitation in the study was the small sample size. A larger sample size would allow for a stronger effect size and potentially the trends for LFnu and HFnu would be statistically significant. However, the sample size was large enough to produce a significant difference in LF-HF ratio.

In conclusion, people with OSA have lower HRV at rest which has been confirmed by previous research. This study found a lower LF-HF ratio during steadystate exercise in the OSA group which may be caused by the blunted parasympathetic response in this population. At rest, the OSA group had a lower starting HFnu variable than the control group, though not statistically significant. The lack of parasympathetic withdrawal in the OSA group could be the association to autonomic dysfunction. Future research with a larger sample group of OSA subjects is necessary to confirm this hypothesis. 


\section{Manuscript References}

1. Somers VK, White DP, Amin R, et al. Sleep apnea and cardiovascular disease: An american heart association/american college of cardiology foundation scientific statement from the american heart association council for high blood pressure research professional education committee, council on clinical cardiology, stroke council, and council on cardiovascular nursing. in collaboration with the national heart, lung, and blood institute national center on sleep disorders research (national institutes of health). Circulation. 2008;118(10):1080-1111.

2. Seetho IW, Wilding JP. Screening for obstructive sleep apnoea in obesity and diabetes-potential for future approaches. Eur J Clin Invest. 2013;43(6):640-655.

3. Malhotra A, White DP. Obstructive sleep apnoea. Lancet. 2002;360(9328):237-245.

4. Song MK, Ha JH, Ryu SH, Yu J, Park DH. The effect of aging and severity of sleep apnea on heart rate variability indices in obstructive sleep apnea syndrome. Psychiatry Investig. 2012;9(1):65-72.

5. Babaeizadeh S, White DP, Pittman SD, Zhou SH. Automatic detection and quantification of sleep apnea using heart rate variability. J Electrocardiol. 2010;43(6):535-541.

6. Young T, Skatrud J, Peppard PE. Risk factors for obstructive sleep apnea in adults. JAMA. 2004;291(16):2013-2016. 
7. Dong JY, Zhang YH, Qin LQ. Obstructive sleep apnea and cardiovascular risk: Metaanalysis of prospective cohort studies. Atherosclerosis. 2013;229(2):489-495.

8. Kardassis D, Grote L, Sjostrom L, Hedner J, Karason K. Sleep apnea modifies the long-term impact of surgically induced weight loss on cardiac function and inflammation. Obesity (Silver Spring). 2013;21(4):698-704.

9. Banhiran W, Junlapan A, Assanasen P, Chongkolwatana C. Physical predictors for moderate to severe obstructive sleep apnea in snoring patients. Sleep Breath. 2013.

10. Young T, Peppard PE, Gottlieb DJ. Epidemiology of obstructive sleep apnea: A population health perspective. Am J Respir Crit Care Med. 2002;165(9):1217-1239.

11. Hudgel DW. Mechanisms of obstructive sleep apnea. Chest. 1992;101(2):541-549.

12. Narkiewicz K, Somers VK. Sympathetic nerve activity in obstructive sleep apnoea. Acta Physiol Scand. 2003;177(3):385-390.

13. Cooper VL, Bowker CM, Pearson SB, Elliott MW, Hainsworth R. Effects of simulated obstructive sleep apnoea on the human carotid baroreceptor-vascular resistance reflex. J Physiol. 2004;557(Pt 3):1055-1065.

14. Freet CS, Stoner JF, Tang X. Baroreflex and chemoreflex controls of sympathetic activity following intermittent hypoxia. Auton Neurosci. 2013;174(1-2):8-14. 
15. Zhu K, Chemla D, Roisman G, et al. Overnight heart rate variability in patients with obstructive sleep apnoea: A time and frequency domain study. Clin Exp Pharmacol Physiol. 2012;39(11):901-908.

16. Kufoy E, Palma JA, Lopez J, et al. Changes in the heart rate variability in patients with obstructive sleep apnea and its response to acute CPAP treatment. PLoS One. 2012;7(3):e33769.

17. Shiau YH, Sie JH, Li SP. Detecting sleep apnea by volatility clustering of heart rate variability. Int J Cardiol. 2013.

18. Hargens TA, Guill SG, Zedalis D, Gregg JM, Nickols-Richardson SM, Herbert WG. Attenuated heart rate recovery following exercise testing in overweight young men with untreated obstructive sleep apnea. Sleep. 2008;31(1):104-110.

19. Chien MY, Lee P, Tsai YF, Yang PC, Wu YT. C-reactive protein and heart rate recovery in middle-aged men with severe obstructive sleep apnea. Sleep Breath. 2012;16(3):629-637.

20. Nanas S, Sakellariou D, Kapsimalakou S, et al. Heart rate recovery and oxygen kinetics after exercise in obstructive sleep apnea syndrome. Clin Cardiol. 2010;33(1):4651.

21. Kaleth AS, Chittenden TW, Hawkins BJ, et al. Unique cardiopulmonary exercise test responses in overweight middle-aged adults with obstructive sleep apnea. Sleep Med. 2007;8(2):160-168. 
22. Beckerman J, Wu T, Jones S, Froelicher VF. Exercise test-induced arrhythmias. Prog Cardiovasc Dis. 2005;47(4):285-305.

23. Cicek D, Lakadamyali H, Gokay S, Sapmaz I, Muderrisoglu H. Effect of obstructive sleep apnea on heart rate, heart rate recovery and QTc and P-wave dispersion in newly diagnosed untreated patients. Am J Med Sci. 2012;344(3):180-185.

24. James CA, Bhonsale A, Tichnell C, et al. Exercise increases age-related penetrance and arrhythmic risk in arrhythmogenic right ventricular dysplasia/cardiomyopathyassociated desmosomal mutation carriers. J Am Coll Cardiol. 2013;62(14):1290-1297.

25. Kosowsky BD, Lown B, Whiting R, Guiney T. Occurrence of ventricular arrhythmias with exercise as compared to monitoring. Circulation. 1971;44(5):826-832.

26. Katritsis, D. and Camm, A. Nonsustainted ventricular tachycardia: Where do we stand? Eur.Heart J. 2004;25(13):1093-1094-1099.

27. Ludka O, Konecny T, Somers V. Sleep apnea, cardiac arrhythmias, and sudden death. Tex Heart Inst J. 2011;38(4):340-343.

28. Hersi AS. Obstructive sleep apnea and cardiac arrhythmias. Ann Thorac Med. 2010;5(1):10-17.

29. Pescatello LS, Arena R, Riebe D, Thompson PD, eds. ACSM's guidelines for exercise testing and prescription. 9th ed. Philadelphia, PA: Lippincott, Williams, and Wilkins; 2013. 
30. Hart TL, Swartz AM, Cashin SE, Strath SJ. How many days of monitoring predict physical activity and sedentary behaviour in older adults? Int J Behav Nutr Phys Act. 2011;8:62-5868-8-62.

31. Dogru MT, Simsek V, Sahin O, Ozer N. Differences in autonomic activity in individuals with optimal, normal, and high-normal blood pressure levels. Turk Kardiyol Dern Ars. 2010;38(3):182-188.

32. Heart rate variability. standards of measurement, physiological interpretation, and clinical use. task force of the european society of cardiology and the north american society of pacing and electrophysiology. Eur Heart J. 1996;17(3):354-381.

33. Lado MJ, Mendez AJ, Rodriguez-Linares L, Otero A, Vila XA. Nocturnal evolution of heart rate variability indices in sleep apnea. Comput Biol Med. 2012;42(12):11791185.

34. Houle MS, Billman GE. Low-frequency component of the heart rate variability spectrum: A poor marker of sympathetic activity. Am J Physiol. 1999;276(1 Pt 2):H21523.

35. Reyes del Paso GA, Langewitz W, Mulder LJ, van Roon A, Duschek S. The utility of low frequency heart rate variability as an index of sympathetic cardiac tone: A review with emphasis on a reanalysis of previous studies. Psychophysiology. 2013;50(5):477487. 
36. National Cholesterol Education Program (NCEP) Expert Panel on Detection, Evaluation, and Treatment of High Blood Cholesterol in Adults (Adult Treatment Panel III). Third report of the national cholesterol education program (NCEP) expert panel on detection, evaluation, and treatment of high blood cholesterol in adults (adult treatment panel III) final report. Circulation. 2002;106(25):3143-3421.

37. Physical activity guidelines for americans. http://www.health.gov/Paguidelines/. Updated 2013. Accessed April/3, 2014.

38. Heart rate variability. standards of measurement, physiological interpretation, and clinical use. task force of the european society of cardiology and the north american society of pacing and electrophysiology. Eur Heart J. 1996;17(3):354-381.

39. Heart rate variability analysis system. http://medicore.com/download/HRV_clinical_manual_ver3.0.pdf. Accessed April 16, 2014.

40. DeGiorgio CM, Miller P, Meymandi S, et al. RMSSD, a measure of vagus-mediated heart rate variability, is associated with risk factors for SUDEP: The SUDEP-7 inventory. Epilepsy Behav. 2010;19(1):78-81.

41. Jagannathan S, D'cruz SM, Selvakumar V, Badanidiyur VR. Heart rate variability in obstructive sleep apnea. International Journal of Biomedical and Advance Research. 2013;04(06):420-421-424. 
42. Kesek M, Franklin KA, Sahlin C, Lindberg E. Heart rate variability during sleep and sleep apnoea in a population based study of 387 women. Clin Physiol Funct Imaging. 2009;29(4):309-315.

43. Narkiewicz K, Montano N, Cogliati C, van de Borne PJ, Dyken ME, Somers VK. Altered cardiovascular variability in obstructive sleep apnea. Circulation. 1998;98(11):1071-1077.

44. Aydin M, Altin R, Ozeren A, Kart L, Bilge M, Unalacak M. Cardiac autonomic activity in obstructive sleep apnea: Time-dependent and spectral analysis of heart rate variability using 24-hour holter electrocardiograms. Tex Heart Inst J. 2004;31(2):132136.

45. Eckberg DL. Sympathovagal balance: A critical appraisal. Circulation. 1997;96(9):3224-3232.

46. Hautala AJ, Kiviniemi AM, Tulppo, MP. Individual responses to aerobic exercise: The role of the autonomic nervous system. Neuroscience and Behvaioral Reviews. 2009;33(2):107-108-115.

47. Alameri H, Al-Kabab Y, BaHammam A. Submaximal exercise in patients with severe obstructive sleep apnea. Sleep Breath. 2010;14(2):145-151.

48. Hartikainen, J., Tahvananien, K., Kuusela, T. Chapter VI: Short-term measurement of heart rate variability. In: Malik M, ed. Clinical guide to cardiac autonomic tests. Netherlands: Kluwer Academic Publishers; 1998:149-150-176. 
49. Guyton, AC, Hall, JE. Chapter 1: Functional organization of the human body and control of the "internal environment". In: Textbook of medical physioolgy. 11th ed. Philadelphia: Elsevier Saunders; 2006:6-7.

50. Monahan KD, Leuenberger UA, Ray CA. Effect of repetitive hypoxic apnoeas on baroreflex function in humans. J Physiol. 2006;574(Pt 2):605-613.

51. Narkiewicz K, van de Borne PJ, Pesek CA, Dyken ME, Montano N, Somers VK. Selective potentiation of peripheral chemoreflex sensitivity in obstructive sleep apnea. Circulation. 1999;99(9):1183-1189.

52. O'Brien LM, Gozal D. Autonomic dysfunction in children with sleep-disordered breathing. Sleep. 2005;28(6):747-752.

53. Ludka O, Konecny T, Somers V. Sleep apnea, cardiac arrhythmias, and sudden death. Tex Heart Inst J. 2011;38(4):340-343.

54. Smith ML, Pacchia CF. Sleep apnoea and hypertension: Role of chemoreflexes in humans. Exp Physiol. 2007;92(1):45-50. 
Table 1-Subject Characteristics

\begin{tabular}{llll}
\hline Characteristic & $\begin{array}{l}\text { OSA } \\
(\mathbf{n = 1 0})\end{array}$ & $\begin{array}{l}\text { CONTROL } \\
(\mathbf{n = 1 6})\end{array}$ & P \\
\hline Age & $43.7 \pm 12.2^{*}$ & $25.6 \pm 9.5$ & $<0.05$ \\
AHI & $29.9 \pm 23.5^{*}$ & $1.4 \pm 1.5$ & $<0.05$ \\
ESS & $8.6 \pm 5.6$ & $9.4 \pm 5.6$ & 0.71 \\
Weight $(\mathrm{kg})$ & $103.4 \pm 23.6^{*}$ & $84.2 \pm 11.5$ & $<0.05$ \\
BMI $(\mathrm{kg} 2 / \mathrm{m} 2)$ & $34.3 \pm 6.0^{*}$ & $28.9 \pm 3.2$ & $<0.05$ \\
Waist Circumference $(\mathrm{cm})$ & $108.9 \pm 14.1^{*}$ & $91.8 \pm 9.3$ & $<0.05$ \\
Neck Circumference $(\mathrm{cm})$ & $42.9 \pm 4.3^{*}$ & $36.4 \pm 3.4$ & $<0.05$ \\
Resting HR & $73.9 \pm 8.6$ & $68.6 \pm 7.8$ & 0.12 \\
SBP & $120.4 \pm 8.4$ & $117.1 \pm 8.4$ & 0.34 \\
DBP & $78.0 \pm 9.2$ & $75.1 \pm 8.0$ & 0.41 \\
\hline
\end{tabular}

Table 1. Data are presented as means \pm Standard Deviation.

$* \mathrm{p}<0.05$

AHI = apnea-hypopnea index; ESS = Epworth Sleepiness Scale; BMI = body mass index; $\mathrm{HR}=$ heart rate; $\mathrm{SBP}=$ systolic blood pressure DBP $=$ diastolic blood pressure 
Table 2-Physical Activity (PA) Data

\begin{tabular}{lll}
\hline Measure of PA & OSA & CONTROL \\
\hline IPAQ (MET-min/week) & $1232.67 \pm 1312.91$ & $2395.82 \pm 1329.72$ \\
Number of days/week of PA & $5.40 \pm 0.52$ & $5.07 \pm 0.80$ \\
Number of sedentary bouts/day & $17.82 \pm 4.83$ & $17.20 \pm 6.14$ \\
Time per sedentary bout (min) & $21.80 \pm 3.16$ & $21.32 \pm 4.76$ \\
Sedentary time/day (min) & $586.62 \pm 146.61$ & $564.10 \pm 161.05$ \\
Light PA (min) & $139.48 \pm 70.03$ & $137.64 \pm 50.05$ \\
Lifestyle PA (min) & $75.15 \pm 53.20$ & $47.86 \pm 17.36$ \\
Moderate PA (min) & $31.43 \pm 16.74$ & $30.45 \pm 17.37$ \\
Vigorous PA (min) & $1.66 \pm 3.69$ & $0.93 \pm 1.32$ \\
Very Vigorous PA (min) & $0.00 \pm 0.00$ & $0.05 \pm 0.19$ \\
Steps/day & $5486.62 \pm 2524.99$ & $5478.24 \pm 2037.97$ \\
\hline
\end{tabular}

Table 2. Data are presented as means \pm Standard Deviation. No differences between groups.

IPAQ = International Physical Activity Questionnaire 
Table 3 - Sleep Data

\begin{tabular}{llll}
\hline Sleep Variable & OSA & CONTROL & P \\
\hline Sleep Latency (min) & $4.96 \pm 2.87$ & $3.54 \pm 3.82$ & 0.328 \\
Sleep Efficiency (\%) & $79.12 \pm 10.92$ & $88.36 \pm 6.30$ & $0.013^{*}$ \\
Total Sleep Time (min) & $362.89 \pm 79.03$ & $388.50 \pm 55.79$ & 0.351 \\
Number of Awakenings & $19.88 \pm 7.09$ & $14.90 \pm 6.89$ & 0.094 \\
Avg. Length of Awakening (min) $\neq$ & $5.07 \pm 3.30$ & $3.28 \pm 1.03$ & 0.069 \\
Total Time in Bed (min) & $409.35 \pm 25.92$ & $470 \pm 19.39$ & 0.115 \\
Wake After Sleep Onset & $69.17 \pm 15.79$ & $64.20 \pm 12.02$ & 0.830 \\
\hline
\end{tabular}

Table 3. Data are presented as means \pm Standard Deviation.

* Significant, $\mathrm{p}<0.05$

$\neq$ Data adjusted for age. 
Table 4-Oxygen Consumption

\begin{tabular}{|c|c|c|c|c|}
\hline Measured Variables & OSA & CONTROL & $\mathbf{P}$ (intensity) & P (between groups) \\
\hline $\mathrm{VO}_{2 \max }$ prediction & $28.0 \pm 4.7$ & $35.3 \pm 4.4$ & -- & $<0.05^{*}$ \\
\hline Predicted $35 \% \mathrm{VO}_{2} \mathrm{R}$ & $9.4 \pm 2.3$ & $11.4 \pm 1.7$ & -- & $<0.05 *$ \\
\hline Predicted $70 \% \mathrm{VO}_{2} \mathrm{R}$ & $18.4 \pm 3.7$ & $22.8 \pm 3.3$ & -- & $<0.05^{*}$ \\
\hline Oxygen Consumption $\neq$ & $17.26 \pm 2.58^{\circ}$ & $18.03 \pm 2.93^{\circ}$ & $0.00 *$ & 0.913 \\
\hline $\begin{array}{l}\text { Light Intensity } \\
\text { Vigorous Intensity }\end{array}$ & $23.98 \pm 4.83^{\circ}$ & $26.45 \pm 4.77^{\circ}$ & & \\
\hline $\mathrm{RER} \neq$ & & & $0.00 *$ & 0.702 \\
\hline Light Intensity & $0.88 \pm 0.05$ & $0.89 \pm 0.06$ & & \\
\hline Vigorous Intensity & $0.97 \pm 0.04$ & $0.99 \pm 0.05$ & & \\
\hline Systolic BP $\neq(\mathrm{mmHg})$ & & & $0.00 *$ & 0.348 \\
\hline Light Intensity & $180.52 \pm 21.0$ & $157.60 \pm 17.97$ & & \\
\hline Vigorous Intensity & $198.79 \pm 26.05$ & $173.87 \pm 17.44$ & & \\
\hline Diastolic BP (mmHg) & & & 0.105 & 0.067 \\
\hline Light Intensity & $91.46 \pm 11.38$ & $83.33 \pm 9.28$ & & \\
\hline Vigorous Intensity & $94.22 \pm 12.46$ & $84.80 \pm 10.90$ & & \\
\hline
\end{tabular}

Table 4. Data are presented as means \pm Standard Deviation.

* Significant, $\mathrm{p}<0.05$

- Significantly higher than predicted oxygen consumption, $\mathrm{p}<0.001$

$\neq$ Data adjusted for age.

$\mathrm{VO}_{2 \max }=$ maximal oxygen consumption

RER $=$ Respiratory exchange ratio

$\mathrm{BP}=$ Blood pressure 
Table 5-HRV Data

\begin{tabular}{|c|c|c|c|}
\hline \multirow[t]{2}{*}{ HRV Variable } & \multicolumn{3}{|c|}{ Intensity } \\
\hline & Resta & Light & Vigorous \\
\hline \multicolumn{4}{|l|}{ SDNN(ms) *\# } \\
\hline OSA & $1.57 \pm 0.31$ & $0.80 \pm 0.16$ & $0.67 \pm 0.18$ \\
\hline CONTROL & $1.85 \pm 0.29$ & $1.05 \pm 0.27$ & $0.76 \pm 0.41$ \\
\hline \multicolumn{4}{|l|}{$\operatorname{RMSSD}(\mathrm{ms})^{* \#}$} \\
\hline OSA & $1.37 \pm 0.27$ & $0.49 \pm 0.18$ & $0.59 \pm 0.28$ \\
\hline CONTROL & $1.78 \pm 0.37$ & $0.45 \pm 0.12$ & $0.47 \pm 0.25$ \\
\hline \multicolumn{4}{|c|}{ Total Power $\left(\mathrm{ms}^{2}\right)^{* \circ} \#$} \\
\hline OSA & $3.26 \pm 0.65$ & $1.82 \pm 0.49$ & $1.28 \pm 1.44$ \\
\hline CONTROL & $3.79 \pm 0.57$ & $2.24 \pm 0.65$ & $1.44 \pm 0.86$ \\
\hline \multicolumn{4}{|l|}{$\operatorname{VLF}\left(\mathrm{ms}^{2}\right)^{\circ} \#$} \\
\hline OSA & $3.02 \pm 0.76$ & $1.73 \pm 0.53$ & $1.24 \pm 0.34$ \\
\hline CONTROL & $3.44 \pm 0.56$ & $2.17 \pm 0.64$ & $1.40 \pm 0.86$ \\
\hline \multicolumn{4}{|l|}{ LFnu } \\
\hline OSA & $52.36 \pm 18.47$ & $62.39 \pm 20.81$ & $72.66 \pm 19.70$ \\
\hline CONTROL & $40.32 \pm 20.47$ & $51.37 \pm 22.54$ & $66.52 \pm 18.26$ \\
\hline \multicolumn{4}{|l|}{ HFnu } \\
\hline OSA & $47.64 \pm 18.47$ & $37.51 \pm 20.87$ & $48.17 \pm 22.86$ \\
\hline CONTROL & $59.77 \pm 20.47$ & $27.32 \pm 19.71$ & $33.86 \pm 18.10$ \\
\hline \multicolumn{4}{|c|}{ LF-HF Ratio $\left(\mathrm{ms}^{2}\right) * *$} \\
\hline OSA & $2.04 \pm 0.35$ & $2.25 \pm 0.44$ & $2.03 \pm 0.45$ \\
\hline CONTROL & $1.81 \pm 0.40$ & $2.51 \pm 0.45$ & $2.34 \pm 0.39$ \\
\hline \multicolumn{4}{|l|}{$\mathrm{LF}\left(\mathrm{ms}^{2}\right) \neq \#$} \\
\hline OSA & $2.51 \pm 0.58$ & $0.598 \pm 0.36$ & $1.15 \pm 0.75$ \\
\hline CONTROL & $3.03 \pm 0.52$ & $-0.16 \pm 0.34$ & $0.11 \pm 0.86$ \\
\hline \multicolumn{4}{|l|}{$\mathrm{HF}\left(\mathrm{ms}^{2}\right) \ddagger \#$} \\
\hline OSA & $2.46 \pm 0.45$ & $0.34 \pm 0.49$ & $-0.19 \pm 0.49$ \\
\hline CONTROL & $3.22 \pm 0.70$ & $0.65 \pm 0.80$ & $-0.23 \pm 0.82$ \\
\hline
\end{tabular}

${ }^{*} \mathrm{p}<0.05$, significant difference at rest between groups

$* * \mathrm{p}<0.05$, significant main effect for group during exercise

$\# p<0.05$, significant main effect for intensity during exercise

$\neq$ adjusted for age at rest.

${ }^{\circ}$ adjusted for age during exercise.

$a$ rest data collected on a different day then exercise data. 
Figure 1-LFnu (A), HFnu (B), and LF-HF Ratio (C) between OSA and Control at rest, light intensity, and vigorous intensity
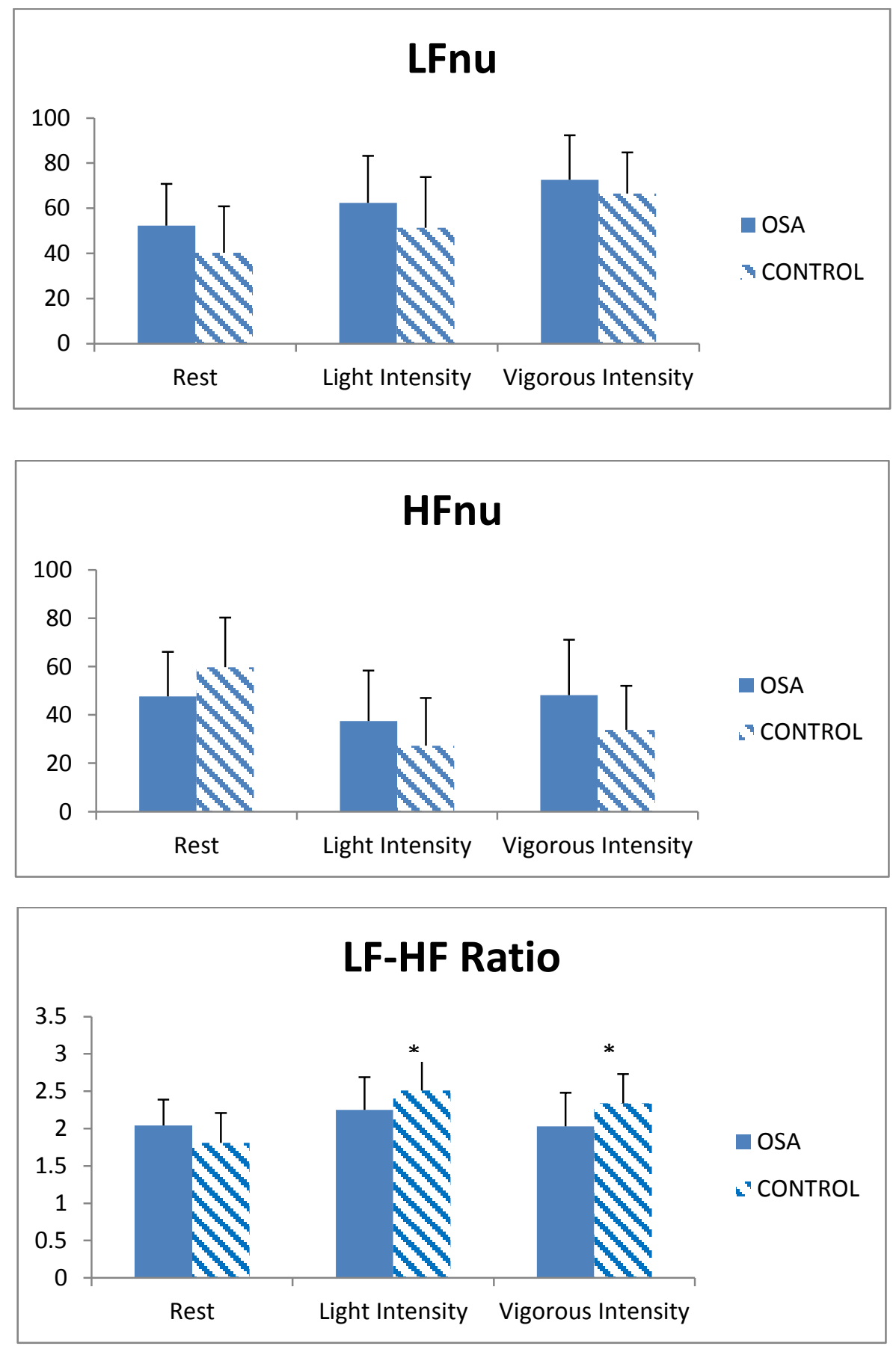

All figures presented as means \pm SD.

$* \mathrm{p}<0.05$, LF-HF ratio is significantly lower in the OSA group compared to the control group.

A. During exercise, LFnu is trending higher in the OSA group towards a main effect for group.

B. During exercise, HFnu is trending higher in the OSA group towards a main effect for group. 
Appendix A:

Informed Consent 


\author{
James Madison University \\ Department of Kinesiology \\ Informed Consent
}

\title{
Purpose
}

You are being asked to volunteer for a research project conducted by Dr. Trent Hargens from James Madison University entitled, "The effects of obstructive SLEEP apnea on AUTONOMIC and cardiovascular FUNCTION during steady-state EXERCISE", or the SAFE study.

The primary goals of this study is to examine whether individuals who are newly identified as high risk for, or diagnosed with, obstructive sleep apnea (OSA) have show altered heart rate and cardiovascular variables during sub-maximal exercise. This may provide a clearer picture into why OSA increases the risk for other chronic health problems.

\section{Experimental Procedures}

You will be asked to visit the Human Performance Laboratory (HPL) in Godwin Hall 3 times over the course of about $7-10$ days. Your total time commitment for participation in this study will be approximately 2 and a half hours. In addition, you will be asked to wear (for one night) an at-home sleep testing device (the ApneaLink) to screen you for possible OSA. It is equipped with straps, a finger probe, and a nasal cannula. It measures your breathing activity, heart rate, and blood oxygen levels, and is harmless to wear. Also, you will be asked to wear a device (an accelerometer) on your waist during the day for a period of 4 days, including 1 weekend day, while wearing the same device on your wrist at night while you sleep. Detailed information on each visit is provided below:

\section{Visit 1}

Before any test is given, you will be asked to complete a screening form and an informed consent, to insure that you meet the study criteria, that you do not have any factors that would disqualify you from participation. Upon completion of the informed consent, you will be asked to complete a short health history questionnaire providing information about your characteristics and health. You will then be asked complete 3 standardized questionnaires about snoring, the quality of your sleep, daytime sleepiness, and risk for OSA.

You will then have your height, weight, waist circumference and neck circumference measured. After that, your body composition will be analyzed via a Dual-energy x-ray absorptiometer (DEXA). The DEXA scan will allow us to measure your percent body fat and the mineral content and density of your bones. The DEXA is much like an X-ray machine. The DEXA will scan your entire body very slowly; so, you will need to lie on a table without moving for almost 10 minutes, while the DEXA is passed over your entire body. You will feel no discomfort associated with this test. 
At the end of this first visit you will also be instructed on the proper use procedures for wearing the ApneaLink device for your one-night sleep assessment, as well as instructions on wearing the accelerometer. An accelerometer is a small device that is to be worn on your waist during the day and on your wrist while in bed.

Following the DEXA scan, we will ask that you wear a heart rate monitor while lying down in a darkened room for 15 minutes to get measures of your heart rate. We will also obtain your resting blood pressure.

\section{$\underline{\text { Visit } 2}$}

The following day after Visit 1, you will be asked to return to the HPL to return the ApneaLink device. Following this, we will ask that you wear a heart rate monitor while lying down in a darkened room for 15 minutes to get measures of your heart rate. We will also obtain your resting blood pressure. This visit should take about 30 minutes.

\section{$\underline{\text { Visit } 3}$}

Approximately 5 - 6 days later, you will be asked to return to the HPL for your final visit. For this visit you will undergo a submaximal treadmill exercise test. You will be asked to walk on the treadmill for a total of about 15 minutes, which includes a $3-4$ minute warm-up, and $2-3$ minute cool-down. In between the warm-up and cool-down you will be asked to walk at 2 separate workloads, 1 fairly easy, and 1 somewhat hard, for 5 minutes at each workload. During this test we will monitor the electrical output of your heart by placing electrodes directly on your skin across your chest, stomach and back. A female researcher will be available to place and remove electrodes for female subjects. During the test, we will measure the electrical activity of your heart, your heart rate, blood pressure, your effort, and how much oxygen your body is using. To see how much oxygen you use, we will ask you to breathe into a rubber mouthpiece. . During the test, you will breathe only through the mouthpiece and may experience some dryness in your mouth. Prior to your arrival to the HPL for this visit, you will be asked to consume a normal meal (breakfast or lunch) and not to come to the HPL with a full stomach.

\section{Risks}

There are no risks associated with wearing an accelerometer. Also, there is no risk associated with heart rate, blood pressure, height, weight, and waist and neck circumference measures. You will not be asked to change any of your personal habits during the course of the study. Measurements with associated risks include: the DEXA scan and treadmill exercise test.

The amount of radiation that you will receive in the DEXA exam is less than the amount you will receive during a transatlantic flight, and is equal to about 1/20 of a chest $\mathrm{X}$-ray. You should not be pregnant for this study because of risks from the DEXA scan radiation to the embryo or fetus. If you feel that you might be pregnant, inform the research staff immediately.

There is a risk of abnormal changes during the submaximal treadmill exercise test. These changes may include abnormal blood pressure, fainting, heart rhythm disorders, stroke, 
heart attack, and death. The chance of serious heart problems during maximal exercise among adults is very small (less than 1/10,000 maximal exercise tests). The exercise trial for this proposed study is sub-maximal vs. maximal, so the risk for complications is even less. Every effort will be made to minimize risks of an abnormal response by reviewing you health history and providing adequate supervision of the exercise test. All staff are certified by the American Heart Association in BLS (Basic Life Support).

\section{Benefits}

There is no guarantee that you will get any benefit from taking part in this study. Benefits may include knowledge about your health status. You will receive information on your body composition, including percent body fat and bone mineral density, an assessment of your sleep quality and risk for sleep apnea, an assessment of your physical activity level, and cardiovascular fitness. Indirect benefits of participating in this study will be helping the researchers better understand the relationship between habitual snoring, sleep apnea, and cardiovascular disease risk.

\section{Inquiries}

If you have any questions or concerns or you would like to receive a copy of the final aggregate results of this study, please contact Dr. Trent Hargens at hargenta@jmu.edu or (540) 568-5844.

\section{Questions about Your Rights as a Research Subject}

Dr. David Cockley

Chair, Institutional Review Board

James Madison University

(540) 568-2834

cocklede@jmu.edu

\section{Confidentiality}

All data and results will be kept confidential. You will be assigned an identification code. At no time will your name be identified with your individual data. The researcher retains the right to use and publish non-identifiable data. All data will be kept secured in a locked cabinet. All electronic data will be kept on a password-protected computer. Final aggregate results will be made available to participants upon request.

\section{Freedom of Consent}

Your participation is entirely voluntary. You are free to choose not to participate. Should you choose to participate, you can withdraw at any time without consequences of any kind. 
I have read this consent form and I understand what is being requested of me as a participant in this study. I freely consent to participate. I have been given satisfactory answers to my questions. The investigator provided me with a copy of this form. I certify that I am at least 18 years of age.

Name of Subject (Printed)

Name of Subject (Signed)

Date
Name of Researcher (Printed)

Name of Researcher (Signed)

Date 


\section{Appendix B:}

Epworth Sleepiness Scale 
Epworth Sleepiness Scale

Subject ID Date Completed 1

This questionnaire asks you to indicate the chances of you becoming drowsy during hours of the day that you are not in bed sleeping. "How likely are you to doze off or fall asleep in the following situations?"

Use the following scale and indicate the most appropriate number for each situation.

$$
\begin{aligned}
& 0=\text { would never doze } \\
& 1=\text { slight chance of dozing } \\
& 2=\text { moderate chance of dozing } \\
& 3=\text { high chance of dozing }
\end{aligned}
$$

\section{Situation}

1. Sitting and reading

2. Watching T.V.

3. Sitting, inactive in a public place

(ex. Theatre or meeting)

4. As a passenger in a car for

an hour without a break

5. Lying down to rest in the afternoon

when circumstances permit

6. Sitting and talking with someone

7. Sitting quietly after a lunch without alcohol

\section{Chance of Dozing}


8. In a car, while stopped for a few minutes in traffic

Sum of Scores, items 1-8 (staff use only) 124 
Appendix C:

Berlin Questionnaire 


\section{Berlin Questionnaire}

Subject ID Date Completed

Height $(\mathrm{cm})$

Weight (kg)

Age

Please choose the correct response to each question.

\section{Category 1}

\section{Do You Snore?}

$\square$ a. Yes

b. No

c. Don't know

If you snore:

\section{Your snoring is:}

$\square$ a. Slightly louder than breathing

b. As loud as talking

c. Louder than talking

d. Very loud - can be heard in adjacent rooms

\section{How often do you snore?}

$\square$ a. Nearly every day

b. 3-4 times a week

c. 1-2 times a week

d. 1-2 times a month

e. Never or nearly never 
4. Has your snoring every bothered other people?

a. Yes

b. No

c. Don't Know

5. Has anyone noticed that you quit Breathing during your sleep?

a. Nearly every day

b. 3-4 times a week

c. 1-2 times a week

d. 1-2 times a month

e. Never or nearly never

\section{Category 2}

6. How often do you feel tired or fatigued after you sleep?

a. Nearly every day

b. 3-4 times a week

c. 1-2 times a week

d. 1-2 times a month

e. Never or nearly never

7. During your waking time, do you feel tired, fatigued or not up to par?

a. Nearly every day

b. 3-4 times a week

c. 1-2 times a week

d. 1-2 times a month

e. Never or nearly never 
8. Have you ever nodded off or fallen asleep while driving a vehicle?

$\square$ a. Yes

$\square$ b. No

If yes:

9. How often does this occur?

a. Nearly every day

$\square$ b. 3-4 times a week

c. 1-2 times a week

$\square$ d. 1-2 times a month

e. Never or nearly never

\section{Category 3}

10. Do you have high blood pressure?

$\square$ a. Yes

b. No

c. Don't Know 
Appendix D:

STOP Questionnaire 
STOP Questionnaire

Subject ID

Date Completed

Height (Inches)

Weight (lbs)

Age

Neck Circumference $(\mathrm{cm})$

The STOP Test consists of four questions:

\section{Snoring}

Do you snore loudly (louder than talking or loud enough to be heard through closed door)?

Yes No

2. Tired

Do you often feel tired, fatigued or sleepy during the day?

Yes No

3. Observed

Has anyone observed you stop breathing during your sleep?

Yes No

\section{Blood Pressure}

Do you have or are you being treated for high blood pressure? Yes No

High risk of OSA: answering yes to two or more questions

Low risk of OSA: answering yes to less than two questions 
Appendix E:

Health History Questionnaire 


\section{Medical and Health History Form}

Name:

Date of Birth:

Ethnicity:

Height: ft Weight: pounds

Gender: Female Male

Campus Address:

Campus Telephone Number:

Campus Email Address:

Address for Permanent Residence:

Person to contact in case of emergency:

Relationship: Daytime Telephone: Home Telephone:

Primary Care Physician:

Telephone:

\section{Medical History}

Please indicate any current or previous conditions or problems you have experienced or have been told by a physician you have had:

Yes

Heart disease or any heart problems:

Rheumatic fever:

Respiratory disease or breathing problems:

Circulation problems:

Kidney disease or problems:

Urinary problems:

Reproductive problems:
No

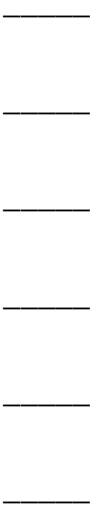


Musculoskeletal problems:

Fainting or dizziness, especially with exertion:

Neurological problems/disorders:

High blood pressure:

Low blood pressure:

High blood cholesterol:

Diabetes:

Thyroid problems:

Eating disorders (bulimia, anorexia):

Allergies:

If "yes" to any of the above please indicate the date, explain, and describe:

Please list any hospitalizations/operations/recent illnesses (Type/Date):

Do you ever feel faint, short of breath, or chest discomfort with exertion? Yes:

No:

If "yes", please explain :

Are there any orthopedic limitations you have that may restrict your ability to perform hard running exercise or intense strength-type exercises? (back, hips, knees, ankles) Yes

No

If "yes" please explain: 


\section{Family Health History}

Has anyone in your family (blood relatives only) been diagnosed or treated for any of the following?

$$
\text { Yes No Relationship Age }
$$

Heart attack

Heart disease

High blood pressure

Stroke

Kidney disease

Diabetes

\section{Health Habits}

Do you add salt to your food? Yes No Are you on any special type of diet? Yes No If "yes" please describe

Do you drink caffeinated beverages? Yes No How many cups per day?

Do you drink alcoholic beverages? Yes No How many drinks per week?

What is the average number of drinks that you consume on the weekend?

Did you use tobacco products in the past (more than 12 months ago)? Yes No

\section{Sleep Habits Evaluation}

Do you have episodes of parasomnias (disorders such as sleep walking, sleep talking, night terrors, body rocking, bedwetting that will cause partial or full awakening?) Yes No_

Do you show signs of sleep disturbances (such as insomnia, daytime sleepiness) when you are anxious, stressed?

Yes No

Do you have difficulties to fall asleep if a certain object or a certain situation is absent such as listening to the radio, watching the television, etc? Yes No 
Do you have difficulties to fall asleep earlier or later of your usual bedtime? Yes No

Do you wake up at night to get a little snack? Yes No

If "yes", do you think that the snack is helping you to go back to sleep? Yes No

Do you have hallucinations (vivid images that look like dreams occurring when you sleep) or find yourself physically weak or paralyzed for a few seconds?

Yes No

\section{$\underline{\text { Tonsils and Adenoids evaluation questionnaire }}$}

Do you have a history of recurrent tonsillitis which is an inflammation of the tonsils (clusters of tissue that lie in bands on both sides of the back of the throat) caused by an infection? In tonsillitis, the tonsils are enlarged, red, and often coated either partly or entirely? Yes No

Did you ever have inflammation of the adenoids (single clump of tissue in the back of the nose) causing a blockage of the back of the nose, chronic and recurrent fluid or infections of your ears, or chronic or recurrent sinus infections? Yes__ No

Did you have tonsillectomy (tonsils removed) or adenoidectomy (adenoids removed)? Yes No

\section{Medications}

Please list all medications (prescription and over-the-counter) you are currently taking or have taken in the past week:

Please sign to indicate the above information is correct:

Print Name

Follow Up Review and Interview by:
Signature
Date 


\section{Appendix F:}

International Physical Activity Questionnaire-Short Form (IPAQ-SF) 


\section{INTERNATIONAL PHYSICAL ACTIVITY QUESTIONNAIRE}

We are interested in finding out about the kinds of physical activities that people do as part of their everyday lives. The questions will ask you about the time you spent being physically active in the last 7 days. Please answer each question even if you do not consider yourself to be an active person. Please think about the activities you do at work, as part of your house and yard work, to get from place to place, and in your spare time for recreation, exercise or sport.

Think about all the vigorous activities that you did in the last 7 days. Vigorous physical activities refer to activities that take hard physical effort and make you breathe much harder than normal. Think only about those physical activities that you did for at least 10 minutes at a time.

1. During the last 7 days, on how many days did you do vigorous physical activities like heavy lifting, digging, aerobics, or fast bicycling? days per week

$\square$ No vigorous physical activities $\rightarrow$ Skip to question 3

2. How much time did you usually spend doing vigorous physical activities on one of those days?

hours per day minutes per day

Don't know/Not sure

Think about all the moderate activities that you did in the last 7 days. Moderate activities refer to activities that take moderate physical effort and make you breathe somewhat harder than normal. Think only about those physical activities that you did for at least 10 minutes at a time.

3. During the last 7 days, on how many days did you do moderate physical activities like carrying light loads, bicycling at a regular pace, or doubles tennis? Do not include walking.

days per week

No moderate physical activities $\longrightarrow$ Skip to question 5 
4. How much time did you usually spend doing moderate physical activities on one of those days?

hours per day minutes per day

Don't know/Not sure

Think about the time you spent walking in the last 7 days. This includes at work and at home, walking to travel from place to place, and any other walking that you might do solely for recreation, sport, exercise, or leisure.

5. During the last 7 days, on how many days did you walk for at least 10 minutes at a time?

days per week

$\square$ No walking $\rightarrow$ Skip to question 7

6. How much time did you usually spend walking on one of those days?

hours per day minutes per day

$\square$ Don't know/Not sure

The last question is about the time you spent sitting on weekdays during the last 7 days. Include time spent at work, at home, while doing course work and during leisure time. This may include time spent sitting at a desk, visiting friends, reading, or sitting or lying down to watch television.

7. During the last 7 days, how much time did you spend sitting on a week day? hours per day minutes per day

$\square$ Don't know/Not sure

This is the end of the questionnaire, thank you for participating. 


\section{References}

1. Somers VK, White DP, Amin R, et al. Sleep apnea and cardiovascular disease: An american heart association/american college of cardiology foundation scientific statement from the american heart association council for high blood pressure research professional education committee, council on clinical cardiology, stroke council, and council on cardiovascular nursing. in collaboration with the national heart, lung, and blood institute national center on sleep disorders research (national institutes of health). Circulation. 2008;118(10):1080-1111.

2. Seetho IW, Wilding JP. Screening for obstructive sleep apnoea in obesity and diabetes-potential for future approaches. Eur J Clin Invest. 2013;43(6):640-655.

3. Malhotra A, White DP. Obstructive sleep apnoea. Lancet. 2002;360(9328):237-245.

4. Song MK, Ha JH, Ryu SH, Yu J, Park DH. The effect of aging and severity of sleep apnea on heart rate variability indices in obstructive sleep apnea syndrome. Psychiatry Investig. 2012;9(1):65-72.

5. Young T, Skatrud J, Peppard PE. Risk factors for obstructive sleep apnea in adults. JAMA. 2004;291(16):2013-2016.

6. Babaeizadeh S, White DP, Pittman SD, Zhou SH. Automatic detection and quantification of sleep apnea using heart rate variability. J Electrocardiol. 2010;43(6):535-541. 
7. Dong JY, Zhang YH, Qin LQ. Obstructive sleep apnea and cardiovascular risk: Metaanalysis of prospective cohort studies. Atherosclerosis. 2013;229(2):489-495.

8. Sankri-Tarbichi AG. Obstructive sleep apnea-hypopnea syndrome: Etiology and diagnosis. Avicenna J Med. 2012;2(1):3-8.

9. Patil SP, Schneider H, Schwartz AR, Smith PL. Adult obstructive sleep apnea: Pathophysiology and diagnosis. Chest. 2007;132(1):325-337.

10. Kardassis D, Grote L, Sjostrom L, Hedner J, Karason K. Sleep apnea modifies the long-term impact of surgically induced weight loss on cardiac function and inflammation. Obesity (Silver Spring). 2013;21(4):698-704.

11. Banhiran W, Junlapan A, Assanasen P, Chongkolwatana C. Physical predictors for moderate to severe obstructive sleep apnea in snoring patients. Sleep Breath. 2013.

12. Friedman M, Tanyeri H, La Rosa M, et al. Clinical predictors of obstructive sleep apnea. Laryngoscope. 1999;109(12):1901-1907.

13. Tsai WH, Remmers JE, Brant R, Flemons WW, Davies J, Macarthur C. A decision rule for diagnostic testing in obstructive sleep apnea. Am J Respir Crit Care Med. 2003;167(10):1427-1432.

14. Young T, Peppard PE, Gottlieb DJ. Epidemiology of obstructive sleep apnea: A population health perspective. Am J Respir Crit Care Med. 2002;165(9):1217-1239.

15. Hudgel DW. Mechanisms of obstructive sleep apnea. Chest. 1992;101(2):541-549. 
16. Isono S, Remmers JE, Tanaka A, Sho Y, Sato J, Nishino T. Anatomy of pharynx in patients with obstructive sleep apnea and in normal subjects. J Appl Physiol (1985). 1997;82(4):1319-1326.

17. Peppard PE, Young T, Barnet JH, Palta M, Hagen EW, Hla KM. Increased prevalence of sleep-disordered breathing in adults. Am J Epidemiol. 2013.

18. Narkiewicz K, Somers VK. Sympathetic nerve activity in obstructive sleep apnoea. Acta Physiol Scand. 2003;177(3):385-390.

19. Bradley TD, Floras JS. Obstructive sleep apnoea and its cardiovascular consequences. Lancet. 2009;373(9657):82-93.

20. Peppard PE, Young T, Palta M, Skatrud J. Prospective study of the association between sleep-disordered breathing and hypertension. N Engl J Med. 2000;342(19):13781384.

21. Wolf J, Lewicka J, Narkiewicz K. Obstructive sleep apnea: An update on mechanisms and cardiovascular consequences. Nutr Metab Cardiovasc Dis. 2007; 17(3):233-240.

22. Cooper VL, Bowker CM, Pearson SB, Elliott MW, Hainsworth R. Effects of simulated obstructive sleep apnoea on the human carotid baroreceptor-vascular resistance reflex. J Physiol. 2004;557(Pt 3):1055-1065.

23. Freet CS, Stoner JF, Tang X. Baroreflex and chemoreflex controls of sympathetic activity following intermittent hypoxia. Auton Neurosci. 2013;174(1-2):8-14. 
24. Zhu K, Chemla D, Roisman G, et al. Overnight heart rate variability in patients with obstructive sleep apnoea: A time and frequency domain study. Clin Exp Pharmacol Physiol. 2012;39(11):901-908.

25. Kufoy E, Palma JA, Lopez J, et al. Changes in the heart rate variability in patients with obstructive sleep apnea and its response to acute CPAP treatment. PLoS One. 2012;7(3):e33769.

26. Shiau YH, Sie JH, Li SP. Detecting sleep apnea by volatility clustering of heart rate variability. Int J Cardiol. 2013.

27. Leti T, Bricout VA. Interest of analyses of heart rate variability in the prevention of fatigue states in senior runners. Auton Neurosci. 2013;173(1-2):14-21.

28. Jagannathan S, D'cruz SM, Selvakumar V, Badanidiyur VR. Heart rate variability in obstructive sleep apnea. International Journal of Biomedical and Advance Research. 2013;04(06):420-421-424.

29. Houle MS, Billman GE. Low-frequency component of the heart rate variability spectrum: A poor marker of sympathetic activity. Am J Physiol. 1999;276(1 Pt 2):H21523.

30. Reyes del Paso GA, Langewitz W, Mulder LJ, van Roon A, Duschek S. The utility of low frequency heart rate variability as an index of sympathetic cardiac tone: A review with emphasis on a reanalysis of previous studies. Psychophysiology. 2013;50(5):477487. 
31. Heart rate variability. standards of measurement, physiological interpretation, and clinical use. task force of the european society of cardiology and the north american society of pacing and electrophysiology. Eur Heart J. 1996;17(3):354-381.

32. Lado MJ, Mendez AJ, Rodriguez-Linares L, Otero A, Vila XA. Nocturnal evolution of heart rate variability indices in sleep apnea. Comput Biol Med. 2012;42(12):11791185.

33. Guzik P, Piskorski J, Awan K, Krauze T, Fitzpatrick M, Baranchuk A. Obstructive sleep apnea and heart rate asymmetry microstructure during sleep. Clin Auton Res. 2013;23(2):91-100.

34. Butner KL, Hargens TA, Kaleth AS, Miller LE, Zedalis D, Herbert WG. Association of obstructive sleep apnea severity with exercise capacity and health-related quality of life. N Am J Med Sci. 2013;5(6):362-366.

35. Chien MY, Chang YJ, Lee P, Yang PC, Wu YT. Electrophysiologic changes with incremental exercise in obstructive sleep apnea. Muscle Nerve. 2013;48(2):212-218.

36. Iftikhar IH, Kline CE, Youngstedt SD. Effects of exercise training on sleep apnea: A meta-analysis. Lung. 2013.

37. Cicek D, Lakadamyali H, Gokay S, Sapmaz I, Muderrisoglu H. Effect of obstructive sleep apnea on heart rate, heart rate recovery and QTc and P-wave dispersion in newly diagnosed untreated patients. Am J Med Sci. 2012;344(3):180-185. 
38. Beckerman J, Wu T, Jones S, Froelicher VF. Exercise test-induced arrhythmias. Prog Cardiovasc Dis. 2005;47(4):285-305.

39. Ludka O, Konecny T, Somers V. Sleep apnea, cardiac arrhythmias, and sudden death. Tex Heart Inst J. 2011;38(4):340-343.

40. Hersi AS. Obstructive sleep apnea and cardiac arrhythmias. Ann Thorac Med. 2010;5(1):10-17.

41. Pescatello LS, Arena R, Riebe D, Thompson PD, eds. ACSM's guidelines for exercise testing and prescription. 9th ed. Philadelphia, PA: Lippincott, Williams, and Wilkins; 2013.

42. Dogru MT, Simsek V, Sahin O, Ozer N. Differences in autonomic activity in individuals with optimal, normal, and high-normal blood pressure levels. Turk Kardiyol Dern Ars. 2010;38(3):182-188.

43. Malliani A, Lombardi F, Pagani M. Power spectrum analysis of heart rate variability: A tool to explore neural regulatory mechanisms. Br Heart J. 1994;71(1):1-2.

44. National Cholesterol Education Program (NCEP) Expert Panel on Detection, Evaluation, and Treatment of High Blood Cholesterol in Adults (Adult Treatment Panel III). Third report of the national cholesterol education program (NCEP) expert panel on detection, evaluation, and treatment of high blood cholesterol in adults (adult treatment panel III) final report. Circulation. 2002;106(25):3143-3421. 